\title{
Seasonal patterns in deep acoustic backscatter layers near vent plumes in the northeastern Pacific Ocean
}

\author{
Brenda J. Burd ${ }^{\text {a }}$ and Richard E. Thomson ${ }^{\mathrm{a}}$ \\ ${ }^{a}$ Institute of Ocean Sciences, P.O. Box 6000, Sidney, BC V8L 5T5, Canada \\ *burdb@dfo-mpo.gc.ca
}

\begin{abstract}
We used moored $75 \mathrm{kHz}$ acoustic Doppler current profilers (ADCPs) to examine seasonal cycles in zooplankton deep scattering layers (DSLs) observed below $1300 \mathrm{~m}$ depth at Endeavour Ridge hydrothermal vents. DSLs are present year-round in the lower water column near vent plumes. Temporal variations suggest passive, flow-induced displacements superimposed on migratory movements. Although the strongest DSLs are shallower than the neutrally buoyant plumes (1900-2100 m), anomalies also occur at and below plume depth. Upward movement from plume depth in the main DSL is evident in late summer/fall, resulting in shallower DSLs in winter, consistent with the timing of adult diapause/reproduction in upper-ocean migratory copepods. Movement from the upper ocean to plume depth coincides with pre-adult migration to greater depths in spring. Synchronous $20-40 \mathrm{~d}$ cycles in DSLs may account for patchiness in space and time of above-plume zooplankton layers observed in summer during previous net-sampling surveys, and suggests lateral and vertical migratory movements to counter current drift away from plume-derived food sources. Persistent nearbottom DSLs move vertically between the spreading plume and seafloor. Historical net data suggests that these are deep, resident fauna. Unlike upper ocean fauna, they seem to be advected considerable distances from the ridge axis, where they are evident as remnant scattering layers.
\end{abstract}

Key words: acoustic backscatter, deep scattering layers, zooplankton, hydrothermal plumes, seasonal patterns

\begin{abstract}
Seasonal patterns in deep acoustic backscatter layers near vent plumes in the northeastern Pacific Ocean. FACETS 4: 183-209. doi: | 0. I I 39/facets-20 I 8-0027

Handling Editor: Daniel E Schindler

Received: July 27, 2018

Accepted: March 4, 2019

Published: June 4, 2019

Copyright: (c) 2019 Burd and Thomson. This work is licensed under a Creative Commons Attribution 4.0 International License (CC BY 4.0), which permits unrestricted use, distribution, and reproduction in any medium, provided the original author(s) and source are credited.
\end{abstract}

Published by: Canadian Science Publishing

\section{Introduction}

Filling gaps in our understanding of carbon cycling in the ocean is becoming increasingly critical as ocean acidification and oxygen declines escalate with climate change. Whether the ocean is a source or sink for excess carbon depends on the balance between organic carbon production and decomposition due to biological metabolism. It has been assumed by researchers that the deep ocean is typically barren (but see Robison 2004), and therefore contributes little to this balance. HernándezLeón and Ikeda (2005) suggested that globally only $20 \%$ of meso-zooplankton and micro-nekton respiration occurs below $200 \mathrm{~m}$, with a total conservatively estimated contribution of $6 \%-10 \%$ of total water column respiration, based on sparse estimates of deep sea meso-zooplankton biomass.

More recent studies are questioning the paradigm that organic input and remineralization is almost entirely limited to the upper $400 \mathrm{~m}$ of the open ocean (Kobari and Ikeda 2001a, 2001b; Ochoa et al. 2013; Burd and Thomson 2015). These studies suggest that deep metazoan aggregations are cycling considerably more carbon and nitrogen than previously accounted for in global carbon budgets. 
For example, deep-sea net studies (Kobari and Ikeda 2001a, 2001b) have shown that considerable numbers of stage V and VI dominant upper ocean copepods (primarily Neocalanus spp.) can be found in diapause to depths of $2000 \mathrm{~m}$ in the northwestern Pacific. Although the copepods were observed at these depths mostly in late summer through winter, and least often in spring to early summer, some adult copepods were found year round. The life-cycle stages and migratory patterns of the same taxa are similar in the northeastern Pacific (Miller et al. 1984; Miller and Clemons 1988; Burd and Thomson 1995), indicating a strong potential for opportunistic use of enhanced sources of organic material in the deep North Pacific (Burd et al. 2002).

A well-established source of nutrients in the northeastern Pacific is the hydrothermal plumes emanating from the seafloor hydrothermal venting region at the Endeavour Segment of Juan de Fuca Ridge (Fig. 1) (Thomson et al. 2005, 2009; Kelley et al. 2012; Bemis et al. 2015) located $300 \mathrm{~km}$ off the British Columbia-Washington coast. Results from several studies (e.g., Cowen et al. 2001; Wakeham et al. 2001; Burd et al. 2002), show that the hydrothermal plumes provide a major food resource for meso-zooplankton in the venting region.

Deep acoustic scattering layers at Endeavour Ridge are associated with laterally spreading hydrothermal plumes (Thomson et al. 1989; Burd et al. 1992; Burd and Thomson 1994, 1995, 2012). A total of 33 oblique tows of an ADCP/transmissometer/multiple-net package were obtained throughout the water column in the summers of 1991 through 1996. The tows provided concurrent (near-field) measurements of acoustic backscatter and net biomass (Burd and Thomson 1993), making it possible to estimate the contribution of the zooplankton aggregations to water column secondary biomass and production (Burd and Thomson 2015). The deep scattering layers found near the hydrothermal

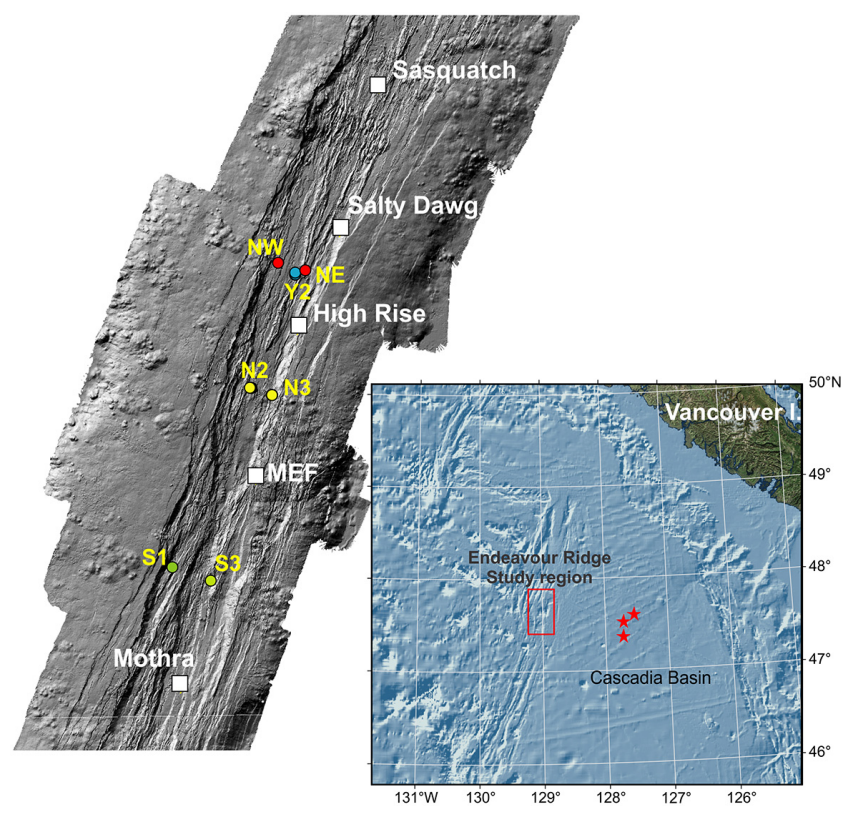

Fig. 1. Map of the Endeavour Ridge venting region off the west coast of Vancouver Island, British Columbia (ESRI rendering of Canadian Hydrographic Service bathymetry data for overview with detailed bathymetry data from D. Kelley, University of Washington, School of Oceanography, Seattle, Washington, USA) showing the locations of the five main hydrothermal vent fields (white boxes) and the mooring sites listed in Table 1. Also shown are the locations of the small vent fields (Mama Bear, Papa Bear, and Baby Bear) in Cascadia Basin (red stars) described by Thomson et al. (1995). 
plumes at Endeavour Ridge in summer are composed of a mixture of highly diverse upper ocean migratory zooplankton and non-migratory species more typical of the deep sea (Burd and Thomson 2015). Copepods consistently make up $~ 80 \%$ of the abundance and almost $50 \%$ of the total water column zooplankton biomass throughout the Endeavour Ridge region, regardless of depth range or proximity to the axial ridge. Upper ocean copepods found near the plumes are dominated by late-stage (V or VI) mesopelagic ontogenetic migrators (particularly the copepods Neocalanus spp. and Eucalanus bungii) and their predators (chaetognaths, fish, and shrimp: Burd and Thomson 1995), typically found at maximum depths of 800-900 $\mathrm{m}$ (the depth of the oxygen minimum layer) in the northeastern Pacific (Miller et al. 1984; Batchelder 1985; Terazaki and Miller 1986; Landry and Fagerness 1988; Miller and Clemons 1988) and all the way to the British Columbia coast (Mackas et al. 2007). The same dominant copepod taxa are found in the northwestern Pacific (Kobari and Ikeda 2001a, 2001b), illustrating that these are ubiquitous and persistent throughout the temperate Pacific. These migratory copepods are rare deeper than $1000 \mathrm{~m}$ outside the general region of the Endeavour Ridge vent fields during the summer, but are a dominant component of the deep scattering layer near the vents (Burd and Thomson 1994, 1995).

The stage $\mathrm{V}$ migratory upper ocean copepods in the open northeast Pacific typically stop feeding in late spring/early summer, then migrate to greater depth to develop eggs and spawn through the winter. The spent adults then die (Goldblatt et al. 1999; Kobari and Ikeda 2001a, 2001b). However, stomach contents of the stage $\mathrm{V}$ migrators collected near the Endeavour Ridge vent plumes show that they are still feeding through the summer at depth (Burd and Thomson 1995). Stable C and $\mathrm{N}$ isotope compositions show a mixture of upper-ocean and vent-derived organic components in their tissue at this time (Burd et al. 2002). Thus, the stage V copepods continue, or resume, feeding near the plumes opportunistically. This increases their reproductive output, as indicated by increased upward flux of zooplankton-derived lipids (Wakeham et al. 2001) and total organic carbon (Cowen et al. 2001) above Endeavour Ridge plumes versus off-axis. Burd and Thomson (2015) also showed that this continued feeding of stage $\mathrm{V}$ zooplankton at depth near the Endeavour Ridge vent plumes results in increased organic biomass and secondary/tertiary production of zooplankton throughout the water column.

The persistence and distribution of the zooplankton aggregations near the vent plumes at Endeavour Ridge have not been studied outside the summer months. Consequently, one of the primary purposes of this study was to determine the persistence of upper ocean dominant migratory copepods and their predators near the vent plumes throughout the year. To this end, we used acoustic backscatter time series from several years of bottom-mounted upward-looking acoustic Doppler current profiler (ADCP) moorings in the region of the vent fields to examine the seasonal and annual distributions of the near-plume scattering layers. The moored ADCP backscatter data, in conjunction with earlier findings from the concurrently towed net and ADCP backscatter sample data from 1991 to 1996, enable us to determine how the deep scattering layers near vent plumes respond to seasonal cycles of dominant taxa in the upper ocean, as well as to variations in the currents in and above the axial valley. A basic premise of the present study is that the dominance of copepods has remained unchanged over the past two decades (Burd and Thomson 1995; Kobari and Ikeda 2001a, 2001b; Mackas et al. 2007) and has unlikely changed substantially since the vent sites first formed more than 2000 years ago (Kelley et al. 2012). A further goal of this study was to discuss the possible contributions of passive advection by currents versus the active movement of the animals, to the observed macro-zooplankton aggregations at Endeavour Ridge.

\section{Methods}

\section{Study area}

Hydrothermal plumes at Endeavour Ridge originate with five major vent fields and multiple sources of diffuse venting within the axial valley of the ridge (e.g., Thomson et al. 2003). The five primary high 
Table 1. Acoustic Doppler current profiler (ADCP) mooring locations and sampling information, including start and end times, durations, sampling rate, and depth range ensonified.

\begin{tabular}{|c|c|c|c|c|c|c|c|c|}
\hline Station & $\begin{array}{c}\text { Latitude } \\
\left({ }^{\circ} \mathbf{N}\right)\end{array}$ & $\begin{array}{c}\text { Longitude } \\
\left({ }^{\circ} \mathrm{W}\right)\end{array}$ & $\begin{array}{l}\text { Bottom } \\
\text { depth (m) }\end{array}$ & $\begin{array}{l}\text { Sampling } \\
\text { start date }\end{array}$ & $\begin{array}{l}\text { Sampling } \\
\text { end date }\end{array}$ & $\begin{array}{c}\text { Number of } \\
\text { sampling } \\
\text { days }\end{array}$ & $\begin{array}{c}\text { Sampling } \\
\text { duration } \\
\text { (min) }\end{array}$ & $\begin{array}{l}\text { Depth } \\
\text { range (m) }\end{array}$ \\
\hline ER03_S1 & 47.93578 & 129.10855 & 2170 & 25 July 2003 & 7 July 2004 & 348 & 60 & $1643-2155$ \\
\hline ER03_S3 & 47.93398 & 129.10125 & 2270 & 25 July 2003 & 7 July 2004 & 348 & 60 & $1743-2255$ \\
\hline ER03_N2 & 47.95868 & 129.09298 & 2220 & 24 July 2003 & 8 July 2004 & 350 & 60 & $1683-2205$ \\
\hline ER04_N2 & 47.95867 & 129.09303 & 2220 & 11 July 2004 & 20 July 2005 & 374 & 60 & $1683-2205$ \\
\hline ER05_N2 & 47.95870 & 129.09323 & 2220 & 22 July 2005 & 2 March 2006 & 223 & 60 & $1683-2205$ \\
\hline ER04_N3 & 47.95773 & 129.08902 & 2170 & 11 July 2004 & 20 July 2005 & 374 & 60 & $1643-2155$ \\
\hline ER05_N3 & 47.95773 & 129.08903 & 2110 & 22 July 2005 & 10 March 2006 & 231 & 60 & 1583-2095 \\
\hline ER04_Y2 & 47.97317 & 129.08423 & 2170 & 10 July 2004 & 20 July 2005 & 375 & 60 & $1643-2155$ \\
\hline ER05_Y2 & 47.97342 & 129.08425 & 2160 & 22 July 2005 & 26 December 2005 & 158 & 60 & $1633-2145$ \\
\hline RCM-NE & 47.97370 & 129.08230 & 2158 & 28 October 2010 & 5 May 2012 & 555 & 15 & $1391-1903$ \\
\hline RCM-NW & 47.97470 & 129.08750 & 2141 & 14 September 2011 & 5 May 2012 & 228 & 15 & $1374-1886$ \\
\hline
\end{tabular}

temperature vent fields (Salty Dawg, High rise, Main Endeavour, Mothra, and Sasquatch) are located at around $2200 \mathrm{~m}$ depth near $47^{\circ} 57^{\prime} \mathrm{N}, 129^{\circ} 06^{\prime} \mathrm{W}$ (Fig. 1; Table 1). All sites are within the axial valley that splits the ridge and all are within the Canadian Endeavour Hydrothermal Vents Marine Protected Area. The high temperature vents and numerous other smaller low temperature vent features in the valley are thoroughly described by Kelley et al. (2012). Temperature and transmissometer profiles at the ridge, along with numerical simulations using nested-grid ocean circulation models (Thomson et al. 2005, 2009) reveal that the rising plumes in the axial valley, augmented by diffuse venting, spread laterally at their level of neutral buoyancy at around 1900-2100 m depth about $200 \mathrm{~m}$ above bottom (mab). Plumes drift both along and across the ridge axis with the prevailing currents (Thomson et al. 2003, 2005, 2009; Xu and Lavelle 2017). Plume remnants are also evident outside the confines of the axial valley and ridge complex, where water depths are much greater (Thomson et al. 1995). Other noteworthy features include a small volcano (Summit Volcano) located near the northern end of the west ridge of the axial valley and a small active vent site on the opposite side of the valley from the volcano (Kelley et al. 2012). Water depths are $<2000 \mathrm{~m}$ over the top of the volcano. Both the topography of the volcano and the hydrothermal fluids from the vent site are expected to affect currents at the northern end of the valley.

\section{Towed ADCP and concurrent net samples}

The towed instrument package used in the historical 1991-1996 biological surveys-consisting of a $153 \mathrm{kHz}$ Teledyne-RDI ADCP, seven opening/closing Tucker trawl nets, a Guildline conductivity, temperature, and depth measurement instrument (CTD), and a transmissometer-as well as data processing, interpretation methods and zooplankton communities throughout the water column are described in Thomson et al. (1991, 1992) and Burd and Thomson (1993, 1994, 1995, 2012, 2015). The ADCP had a downward-looking orientation and the processed data were mainly confined to downcasts to minimize disturbance to flow past the ADCP and CTD. Tows were conducted in July or August at various times of the day and night. Results from this earlier work provide context and descriptions of the deep scattering layer composition near the vent plumes in summer. 


\section{Moorings}

Time-series ADCP records from two separate sets of moorings from different years anchored at depths of 2110 to $2270 \mathrm{~m}$ were utilized to examine backscatter patterns over the lower water column (1375-2200 m depth) in the Endeavour Ridge axial valley. The mooring sets are from the Seabreeze project (ER03-ER05) (Institute of Ocean Sciences, Fisheries and Oceans Canada, Sidney, British Columbia; University of Washington, School of Oceanography, Seattle, Washington State) and Neptune Canada (RCM) (now a component of Ocean Networks Canada, University of Victoria, Victoria, British Columbia). Deployment dates, water depths and depth ranges of the ADCPs are shown in Table 1. All moorings included an upward-looking $75 \mathrm{kHz}$ RDI-Teledyne Workhorse ADCP positioned at the top of the mooring. The four beams of the ADCP were at $30^{\circ}$ angle to the vertical, and at $90^{\circ}$ angles to each other. The ADCPs used during the Seabreeze project recorded a total of 64 bins with bin lengths of $8 \mathrm{~m}$, whereas those used in the Ocean Networks Canada program recorded 128 bins with vertical bin lengths of $4 \mathrm{~m}$. The lateral ensonification spread for the ADCPs used in both projects (calculated as bin length $\times$ bin number) reached a maximum of $512 \mathrm{~m}$ at a distance of $512 \mathrm{~m}$ from the transducer head. Distal bins with low signal/noise backscatter ratios were excluded from analyses. The records from Bin 1 adjacent to the transducer head were also excluded as the data were contaminated by high frequency transducer noise (data from Bin 1 were invariably inconsistent with data from the rest of the profile). There was also an acoustical "blanking range" of $1 \mathrm{~m}$ between Bin 1 and the transducer.

Because the ADCPs were subject to changes in orientation caused by current-induced torque on the moorings, time series from certain beams occasionally showed interference patterns that are likely associated with delayed secondary reflections of transmitted acoustic waves from the nearby valley walls. Although wall interference may have affected current velocity measurements (derived using Doppler frequency shifts of the acoustic signal from each beam; cf. Thomson and Emery 2014), the interference appears to have had a minimal effect on the acoustic backscatter intensity. To ensure that the signal from a disrupted beam is not overly emphasized, we averaged the backscatter data from all four beams. As illustrated by Fig. 2, there was little overall difference in the backscatter patterns among the separate beams.

The moorings can be grouped into three geographic clusters (Fig. 1):

1. Northern end of the axial valley; Seabreeze mooring Y2 and Ocean Networks Canada (ONC) moorings northeast and northwest.

2. Middle of the axial valley; Seabreeze moorings N2 and N3.

3. Southern end of the axial valley; Seabreeze moorings S1 and S3.

ONC moorings are now operating in the southern and central Axial Valley but the time series are presently too short for seasonal analyses.

Based on results from combined net/ADCP profile data collected during the 1990s (Burd and Thomson 1994, 1995), acoustic backscatter profiles obtained from the upward-looking ADCPs mounted at $250 \mathrm{mab}$ in the Neptune moorings may have partially missed some of the plume-related deep scattering layers. Conversely, acoustic profiles from the Seabreeze moorings beginning at 6 mab provide details of the scattering layers above and below the horizontally spreading plume that typically lies between 1700 and $2200 \mathrm{~m}$ depth, but will have missed migratory patterns farther up the water column. By combining results from the two mooring studies and the detailed net zooplankton data available from the earlier shipboard surveys, it is possible to generate a more complete annual cycle of the scattering layers from roughly $1375 \mathrm{~m}$ depth to near-bottom, with the underlying assumption that the deep scattering layer zooplankton patterns remained similar in character (if not detail) over the decade between the moored Seabreeze and Neptune ADCP measurements. 


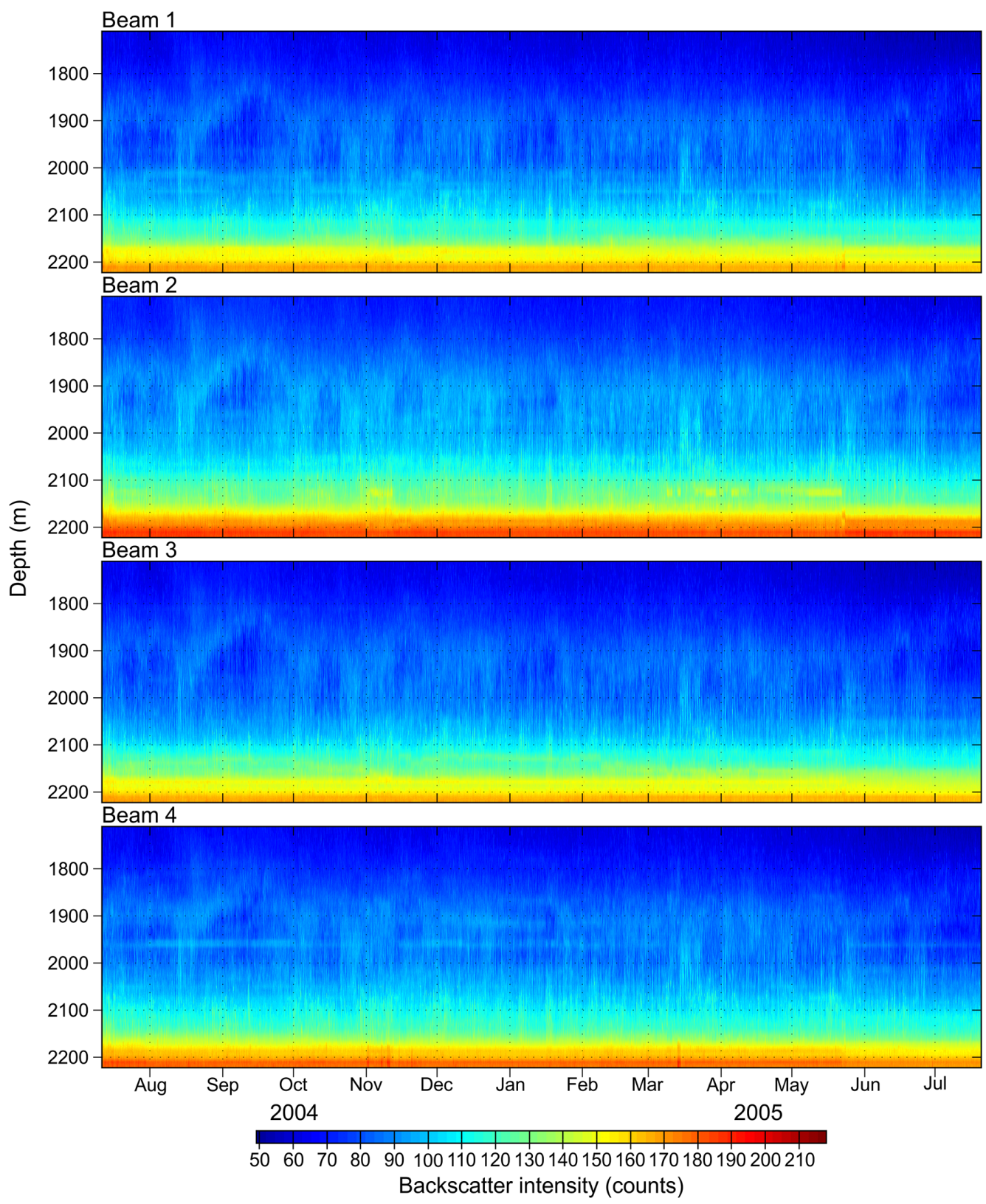

Fig. 2. Time series of the "raw" acoustic backscatter intensity (counts) from the acoustic Doppler current profiler (ADCP) Seabreeze mooring station N2 in the axial valley of Endeavour Ridge (site ER04_N2; Table 1). The ADCP was moored looking upward from $6 \mathrm{~m}$ above the seafloor at a water depth of $2220 \mathrm{~m}$ from 1000 UTC on 20 July 2004 to 1200 UTC on 20 July 2005 (see Table 1 for station coordinates). The ADCP had a sampling rate of $60 \mathrm{~min}$ and a bin length of $8 \mathrm{~m}$. The first bin in the plot is at $2206 \mathrm{~m}$ depth (the first ADCP bin was omitted).

\section{Daily mean backscatter anomalies}

Because the short-term passive transport of zooplankton by the relatively strong $(1-10 \mathrm{~cm} / \mathrm{s})$ tidal currents and other high frequency motions tend to blur active longer-term migratory shifts in backscatter features, a 30-h low-pass Kaiser-Bessel filter (cf. Thomson and Emery 2014) was applied 
to all backscatter time series to remove high-frequency variability. The smoothed time series were then reduced to 24 -h intervals. The resulting daily time series of backscatter intensity for each bin was then averaged and a mean vertical ("background") profile generated for each time series. To construct backscatter anomaly profiles, the mean backscatter value for each bin was subtracted from the daily mean value for that bin. This removal of the vertical background structure is meant to compensate for the well-known, but here undetermined, attenuation in acoustic signal strength due to spherical spreading and absorption of the acoustical energy with distance, $R$, from the ADCP (e.g., Thomson et al. 1991; Deines 1999; Gostiaux and van Haren 2010). Although this process can cause the acoustic backscatter from persistent, near-stationary backscatter layers to be blended into the derived background structure, the effect is mitigated by the marked temporal variability in the layer depths and distributions. As a consequence, acoustic backscatter anomalies associated with zooplankton aggregations ensonified by the moored ADCP are reduced in amplitude but not fully "lost" to the background profile estimates. A more sophisticated method for extracting background acoustic profiles from moored ADCP backscatter time series with steady transducer transmit power is presented in Gostiaux and van Haren (2010). As we are interested in relative temporal changes rather than absolute changes, the methodology has not been applied.

\section{Seabreeze time series}

The Seabreeze program (www2.ocean.washington.edu/seabreeze/sb.pdf) at the Endeavour Segment of Juan de Fuca Ridge was a component of the RIDGE 2000 Integrated Study Site (ISS). Metadata and information on the mooring locations and history can be found at www2.ocean.washington.edu/ seabreeze/sb03/locations and in Table 1.

The Seabreeze instruments were self-contained and powered by internal batteries. Each deployment period lasted for about 1 year (Table 1 ) and consisted of an upward-looking $75 \mathrm{kHz}$ ADCP positioned $6 \mathrm{~m}$ above the seafloor in water depths ranging between 2110 and $2270 \mathrm{~m}$. ADCP data were recorded between July 2003 and March 2006. For all deployments, there was a slight loss in ADCP power output over time, leading to a decrease in the signal-to-noise ratio for the acoustic backscatter time series. This effect was most pronounced for acoustic bins farthest from the instrument, with the range of backscatter counts declining by $0.5 \%$ near the instrument to $14 \%$ at the most distant (shallowest) bin over a typical 12-month deployment. Although the decrease in power output could often be modeled using a 3rd order polynomial (Fig. 3), attempts to fully correct for power loss were hindered by irregular temporal adjustments in the ADCP automatic gain control or other unknown factors associated with the instrument. This effect is clearly illustrated by Fig. 3, which shows the declines in ADCP voltage output (blue line) and backscatter intensity over time for selected bins.

Our inability to accurately correct acoustic backscatter time series for instrument power loss made it impossible to derive absolute backscatter time series for within-deployment and betweendeployment Seabreeze mooring periods. However, because the decrease of instrument power over time was very gradual, short-term changes in backscatter intensity are unlikely to have been affected in any substantial way. As we are mainly interested in seasonal and intra-seasonal changes in backscatter intensity and distribution, the next step was to estimate the effect of power loss by smoothing the daily anomaly series with a 90-d low-pass filter. Estimates of the backscatter anomaly time series for time scales $<3$ months were then calculated by subtracting the low-pass filtered record from the daily averaged data for each bin. The results help mitigate bias from loss in instrument power over time. As discussed in the previous section, acoustic backscatter anomalies associated with zooplankton aggregations are partially reduced in amplitude by subtraction of the binaveraged values. 


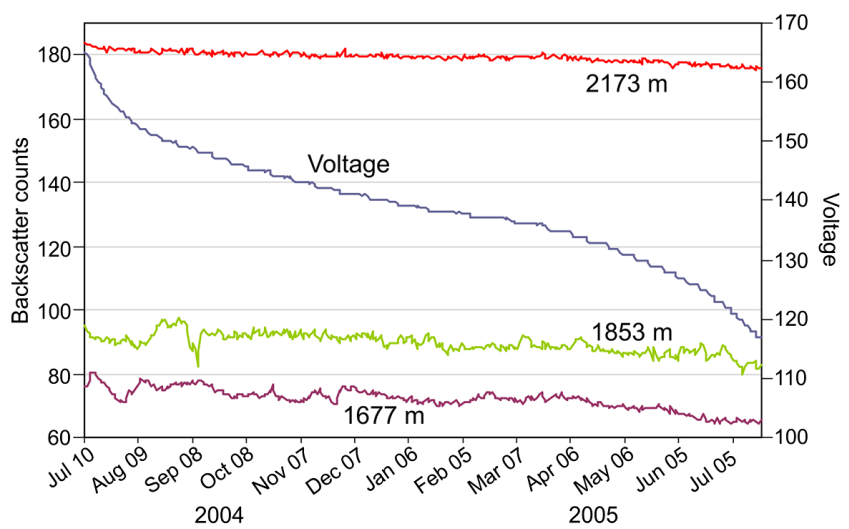

Fig. 3. Time series of the acoustic Doppler current profiler (ADCP) voltage output (blue line) for Seabreeze deployment ER04-Y2 and the corresponding raw backscatter intensity (in counts) for three depth bins at ranges varying from near, intermediate, and distant from the ADCP. The bin at $2173 \mathrm{~m}$ depth was nearest the transducer head, whereas the bin at $1677 \mathrm{~m}$ depth was at the far end of the depth range of the instrument. The time axis is in month/day/year format.

\section{Ocean Networks Canada time series}

The first set of ONC moorings at Endeavour Ridge (sites RCM-NE and RCM-NW) included time series of acoustic backscatter from upward-looking $75 \mathrm{kHz}$ ADCPs obtained via the ONC web-based data access portal. The Endeavour Ridge segment of the cabled observatory is described at oceannetworks.ca/introduction-endeavour and in Table 1. The ADCPs were moored at approximately $1900 \mathrm{~m}$ depth at both locations and the original data series sampled at intervals from $2 \mathrm{~s}$ to $15 \mathrm{~min}$. For consistency among the records, the more rapidly sampled series were re-sampled to 15 min by averaging over each 15-min interval. Because the moorings were powered through the cabled network, there was no ADCP power output loss over time.

The ample power available from the ONC network made it possible to set the ADCPs to the high-power mode. An unexpected consequence of this decision was that acoustic backscatter records from the two instruments were contaminated by cross-interference. This interference, which gave rise to anomalously high backscatter intensity for periods up to $1.5 \mathrm{~h}$, was prevalent from the beginning of October 2011 to 15 February 2012, after which an adjustment in instrument settings was made to considerably reduce the problem. Data collected during the interference periods were "cleaned" using an acoustic threshold level determined individually for each series as the 100th highest value in the series. This method successfully removed many of the larger interference "spikes". Although some weaker interference spikes (with peak values below the specified threshold) still remained in the series, calculation of the backscatter anomalies by subtraction of the time-averaged (background) backscatter intensity value for each bin removed any remaining low amplitude interference. However, because of a power output adjustment made to the ADCP settings on 15 February 2012 by ONC, the time-averaged background backscatter intensity also shifted. Therefore, the backscatter anomalies were calculated by subtracting time-averaged backscatter counts for each bin over the deployment period up to 15 February 2012 at 2000, and then separately for the remainder of the deployment. As with the Seabreeze data, acoustic backscatter anomalies are partially reduced in amplitude by subtraction of bin-averaged values.

\section{Results}

High-frequency tidal and inertial motions are among the most energetic forms of variability at the venting region (Thomson et al. 1990). Forced by surface winds, inertial motions have a period of 
roughly $16.4 \mathrm{~h}$ at the latitude of the moorings and can be especially intense during storms (cf. Thomson et al. 1990; Allen and Thomson 1993). Of the three types of high-frequency motions (diurnal, semidiurnal, and inertial) recorded by the ADCPs, only semidiurnal currents can cause substantial vertical displacements in the acoustic backscatter depths. The vertical displacements of up to $100 \mathrm{~m}$ observed in backscatter layer depth at semidiurnal periods (e.g., Fig. 4) likely arise from the

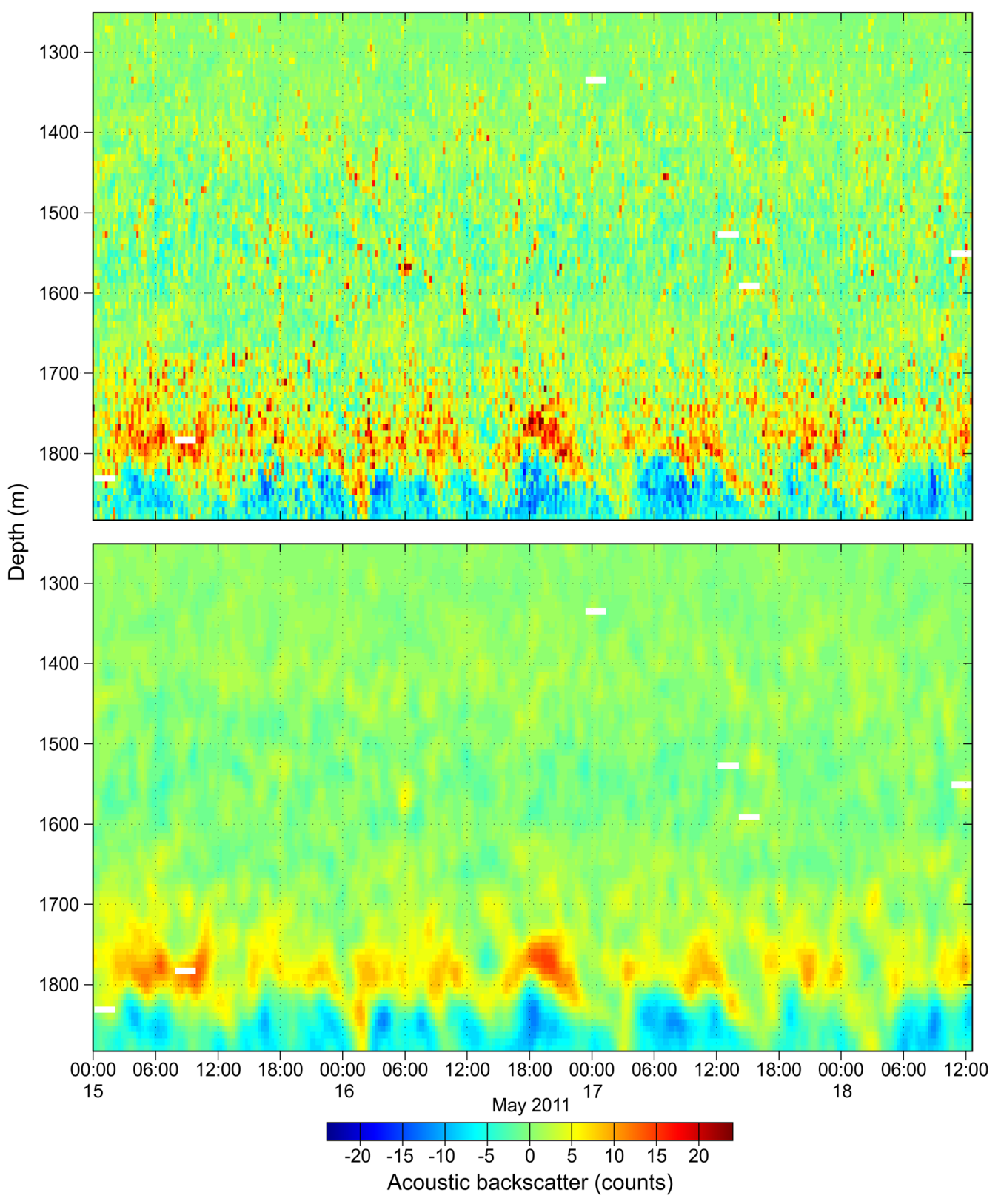

Fig. 4. A 35-d fragment of the backscatter intensity record from Beam 1 of the acoustic Doppler current profiler (ADCP) moored at site RCM-NE during May 2011. The upper panel shows the original series resampled to 15-min averages and the lower panel the series smoothed by a cubic spline in time-depth space. The record shows vertical variations due mainly to up to roughly $100 \mathrm{~m}$ passive vertical movements of the backscatters by semidiurnal internal tidal motions. 
passive movement of the zooplankton during vertical displacements of isopyncal surfaces by internal tides. The effects of these motions, along with those of other forms of high-frequency variability, should be removed by the 30-h low-pass filter applied to the "raw" data.

\section{Vent plume distributions}

Vent plume distributions in the study region consist of output from the major vent fields and diffuse seafloor venting sites within the axial valley of Endeavour Ridge, and output from isolated seafloor venting features to the east of the ridge in Cascadia Basin (Thomson et al. 2009). A compilation of transmissometer profiles from a series of summer tows between 1991 and 1996 in the general vicinity of the ridge (Fig. S1) shows that, following their coalescence, the rising particle-laden thermal plumes from the major vent fields reach a level of neutral buoyancy several hundred mab and then spread laterally in and around the axial valley. The level of neutral buoyancy over the ridge depends on the water depth and initial buoyancy of the plumes, but is typically around 1900-2200 m depth. These plume heights are less than those of mega-plumes generated by major seafloor eruptions, which can rise as high as 1000 mab (e.g., Baker et al. 1989; Dziak et al. 2007) as noted in Tow 95G (Fig. S1).

Figure 5 shows selected transmissometer profiles from summer net tows conducted from 1991 to 1996. The profiles are representative of historical conditions proximal to the three mooring deployment areas in the axial valley (north, middle, and south; see Fig. 1). For the northern group, the plume depth ranged between 1600 and $2200 \mathrm{~m}$, depending on bottom depth, with evidence of suspended particulates extending all the way to the seabed. In the center of the axial valley, the plume depth was more confined, ranging from around 2000 to $2100 \mathrm{~m}$ depth. The southern grouping tended to have variable plume depths in the depth range $1850-2200 \mathrm{~m}$.

\section{Seabreeze moorings}

Because mooring N2 is common to all three Seabreeze deployments, we have used data from this site to represent temporal changes in acoustic backscatter intensity within the Axial Valley. The upwardlooking ADCPs on mooring $\mathrm{N} 2$ revealed acoustic backscatter layers from approximately $1700 \mathrm{~m}$ to near-bottom depths (Fig. 6). Supplementary Material 2 includes the daily anomaly backscatter contour plots for all nine Seabreeze deployments. The strongest backscatter anomalies occurred above $2100 \mathrm{~m}$ depth, the approximate depth of the laterally spreading plumes, but varied considerably in depth and intensity over time. In some cases, a smaller backscatter peak was observed within the plume or below it. These smaller peaks sometimes appeared concurrently with the stronger anomaly above the plume (e.g., deployments ER03-S1 and S3, ER04-N3, and ER05-N2).

At times, we observed a number of fragmented and diffuse backscatter layers spanning the entire depth range ensonified by the ADCP, whereas at other times clearly distinct and vertically compact positive anomalies were observed separated by negative or low positive anomalies (indicative of relatively clear water). For example, deployment ER04-N2 (Fig. 6a) showed anomalies above and below the plume in early July 2004 and 2005. A similar seasonal pattern was evident in other deployments (Supplementary Material 2), including ER03-N2 late summer, ER04-N2 fall and spring ER05-N2 fall, ER04-Y2 late fall, early summer, ER03-S1 early summer, and ER04-N3 late fall.

The backscatter layers identified by ADCPs on the Seabreeze moorings showed signs of seasonal/ ontogenetic vertical migration, a pattern evident to a greater or lesser extent in all of our ADCP deployments. For example, during mid-winter (January-March), the ADCP records show generally much lower overall backscatter anomalies in the deeper portion of the water column, with most of the scatterers positioned at depths $<1600 \mathrm{~m}$. Similarly, the swathes of positive backscatter anomaly observed at depths shallower than $1900 \mathrm{~m}$ in early fall and late spring are indicative of vertical seasonal zooplankton migration. Figure $6 b$ presents a detailed 50-d duration contour plot of the backscatter anomalies for ER04-N2 

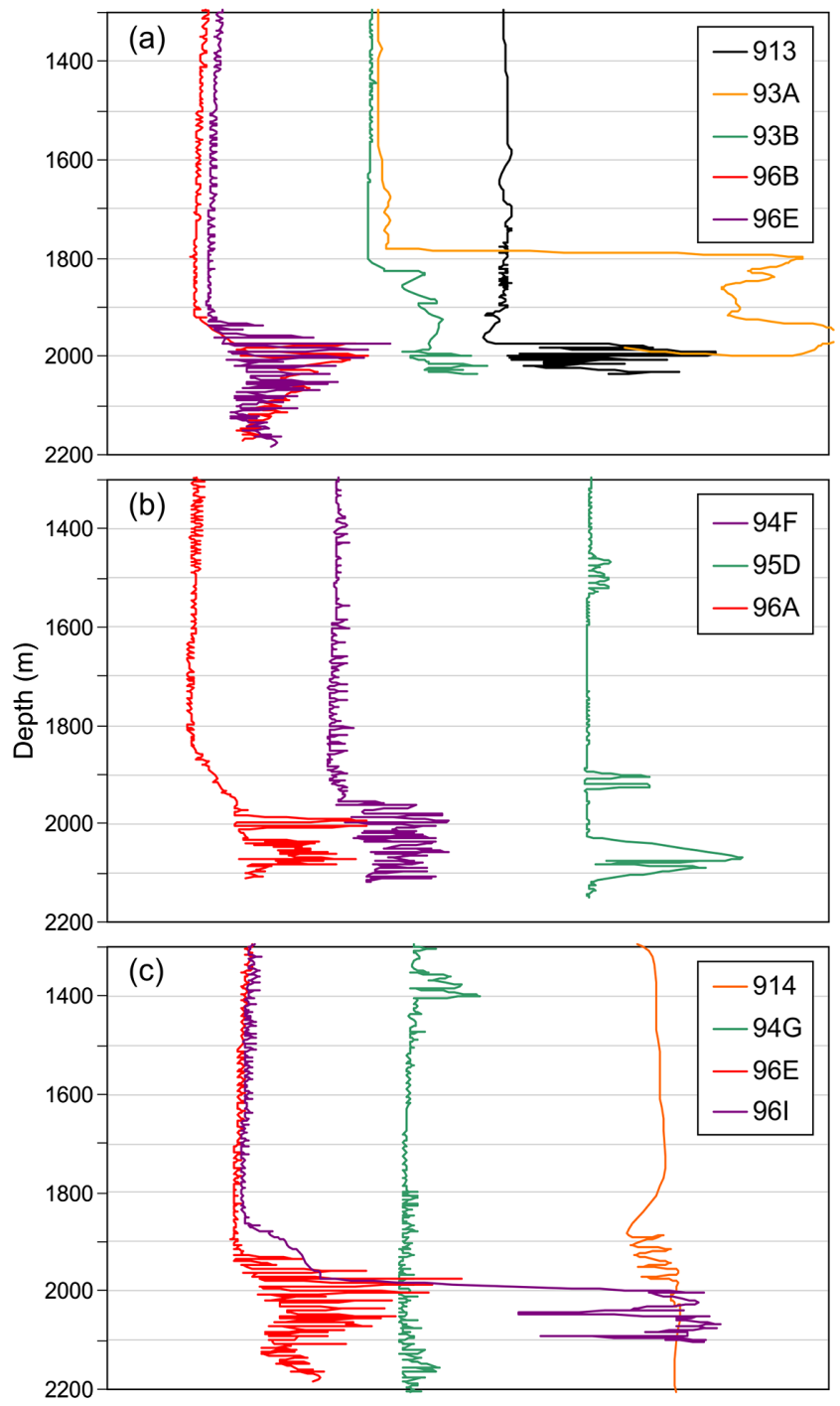

Fig. 5. Examples of transmissometer profiles from four summer tows (1991-1996) from each of: (a) the northern part of the axial valley (near moorings Y2, RCM-NE, and RCM-NW); (b) five tows from the middle of the axial valley (near moorings N2 and N3), and (c) four tows from just south of the axial valley (near moorings S1 and S3). Note that some of the tows show very noisy transmissometer signals, suggesting spatial patchiness in the particle plume. Profiles are identified by year $(94=1994)$ and cast number $(A-I)$.

from August 2004 through mid-October 2004. The intense scattering layer found just above the plume at $1950 \mathrm{~m}$ depth in August is typical of what has been documented in towed summer ADCP profiles from 1991 to 1996 (Burd and Thomson 1994, 1995, 2015). However, by September, this layer appears to have split into two component parts that moved in opposite vertical directions. One layer moved upward in the water column and seemed to disappear above the range of the ADCP, whereas the other layer moved downward, well below the depth of the neutrally buoyant plume.

Comparison of acoustic backscatter time series for different mooring locations within a given year show a striking similarity in the backscatter anomaly pattern above the ridge crests and laterally 

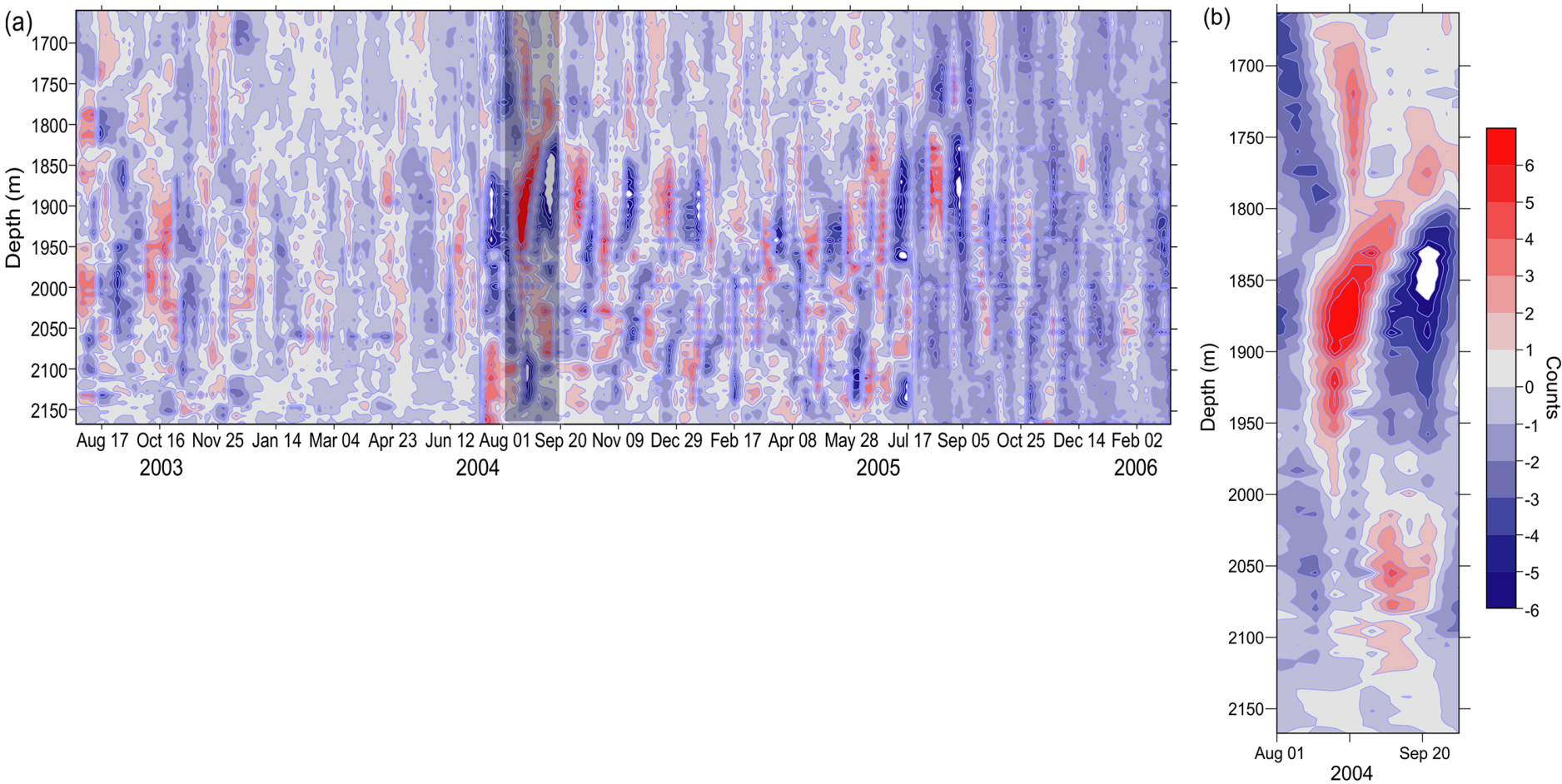

Fig. 6. (a) Acoustic backscatter anomaly time series (colour scale) covering the entire 3-year deployment for Seabreeze deployment ER-N2; and (b) a 50-d duration backscatter anomaly segment (early August to mid October 2004) from the shaded area in $(a)$ above, showing details of how the concentrated scattering layer just above the laterally spreading hydrothermal plume in late August appears to split into two separate components in September.

spreading plume (Fig. 7a), but not below the plume (Fig. 7b). In particular, moorings N2 and N3 had similar temporal patterns, with a slight offset in time between the patterns at those sites at the more northerly mooring, Y2. This suggests that epiplume zooplankton movements tend to be closely synchronized over the entire axial valley, regardless of local differences in plume conditions. Conversely, backscatter anomalies tended to be uniformly low and more randomly distributed near the bottom (>2200 $\mathrm{m}$ depth) amongst mooring locations.

A surface plot of the ER04-N2 backscatter anomaly time series (Fig. 8; same data as Fig. 6a) shows periodic peaks and troughs in the backscatter anomaly values throughout the measured depth range. The cyclic pattern has a periodicity of $20-40 \mathrm{~d}$ and is present in all contour plots from the Seabreeze data (Fig. 6, and see Supplementary Material 2), but is most clearly visible in surface plots. The pattern is most intense in the $1800-1950 \mathrm{~m}$ depth range, but is also present below plume depth. Minimal or reduced intensity of the cyclical patterns are evident in the near-bottom layers below plume depth (>2100 $\mathrm{m}$ depth). In aggregate, the patterns are clearly suggestive of temporal shifts in the concentration and dispersal of organisms over the visible acoustic depth range ( 1375-2000 m; Table 1) ensonified by the combined set of ADCPs.

\section{Ocean Networks Canada moorings}

Because the upward-looking $75 \mathrm{kHz}$ ADCPs on the ONC (formerly Neptune) moorings were positioned $250 \mathrm{~m}$ above the seafloor, the juxtaposition of the deep scattering layers (DSLs) to the hydrothermal plume is only partially observed in the backscatter data. In contrast, the acoustic records from these moorings extend much farther up the water column than the Seabreeze observations, 

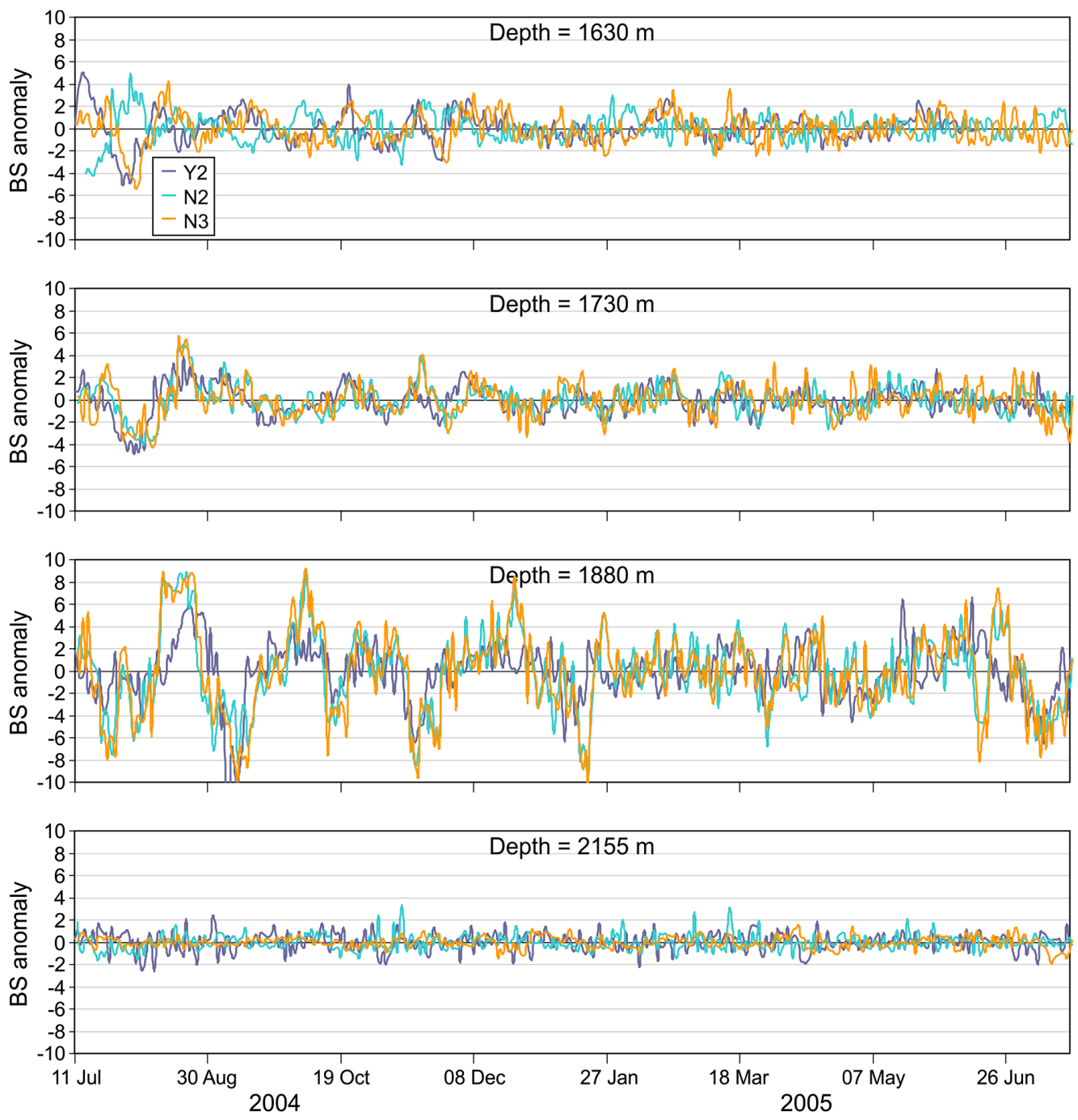

Fig. 7. Backscatter anomalies (counts) at: 1630, 1730, 1880, and $2155 \mathrm{~m}$ depth, for all Seabreeze deployments over the 12 -month period beginning in summer of 2004. Time series are color-coded according to mooring site (see Fig. 1 for locations).

enabling us to examine migrational behaviour in the backscattering layers over the depth range of roughly 1375-1900 m. The backscatter anomalies for the northeast ONC deployment (Fig. 9a) show an aggregation of fauna from 1375 to $1600 \mathrm{~m}$ depth in late winter through late spring 2011 . This was followed by low backscatter anomalies throughout this depth zone from early summer through early fall 2011. Backscatter layers reappeared above $1500 \mathrm{~m}$ depth in mid-fall 2011 and intensified through the winter. By early spring 2012, backscatter anomalies were small throughout the depth range covered by ONC mooring ADCPs. Dispersed backscatter layers re-appeared in mid-spring 2012 and became more pronounced towards late spring (near the end of the deployment). The dispersion of backscatter anomaly layers at different depths suggests that the fauna do not all migrate at the same time, but rather migrate vertically in pulses. The backscatter time series from the shorter northwest ONC deployment (Fig. 9b) shows the same basic pattern as the northeast ONC deployment. Despite the roughly $1 \mathrm{~km}$ separation between the moorings, the similarity between the patterns is striking. 


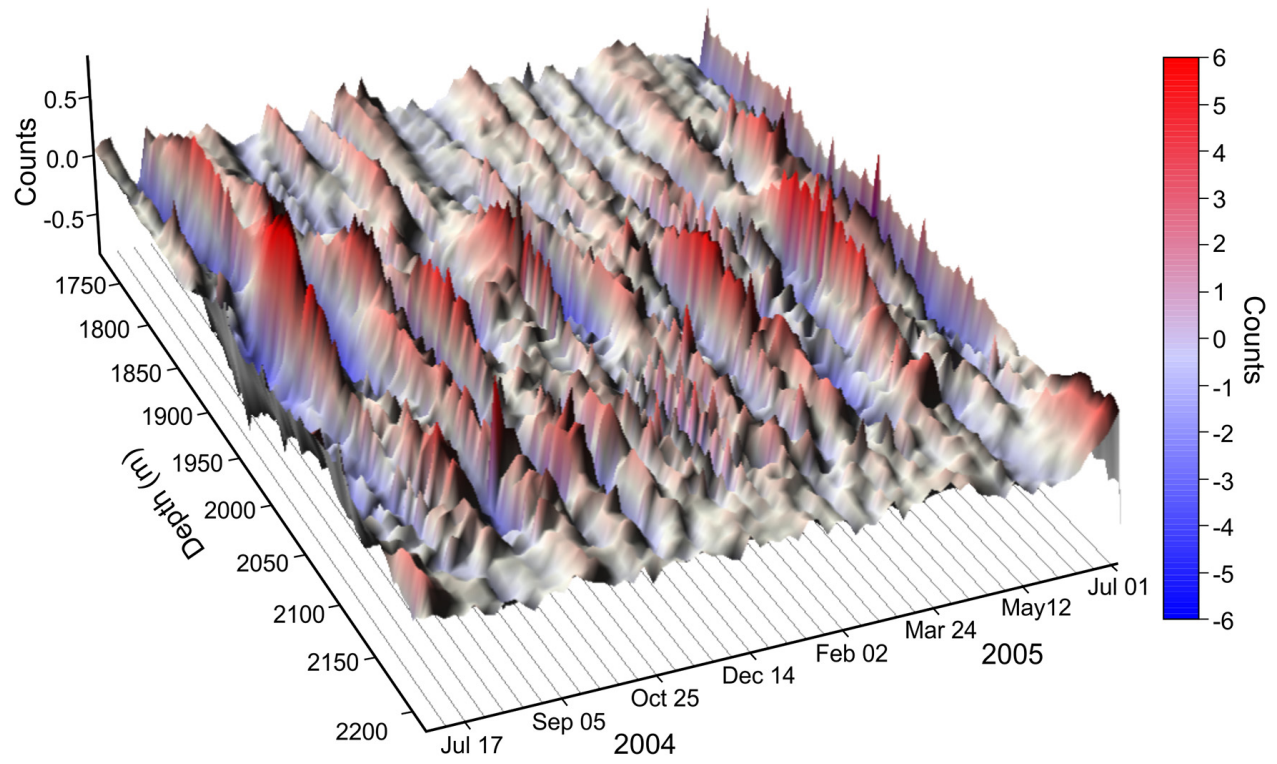

Fig. 8. Surface contour plot based on data from Seabreeze deployment ER04-N2 showing the 20-40 d periodicity of the peaks and troughs of backscatter records (in counts) within and just above the axial valley ridge crests.

As with the Seabreeze moorings, surface contour plots of the backscatter anomalies for the northeast ONC mooring (same data as Fig. 9a) reveal a cyclical pattern of peaks and troughs that is most evident for time-depth regions with higher backscatter anomalies (Fig. 10). This pattern also occurs in the northwest ONC mooring, indicating that horizontal or vertical movement of the organisms occurs on a regular basis with a period of $20-40 \mathrm{~d}$.

\section{Discussion}

Our examination of the multi-year acoustic backscatter records from upward-looking $75 \mathrm{kHz}$ ADCPs moored in the Axial Valley of Endeavour Ridge shows that backscatter layers are present year-round at depths $>1300 \mathrm{~m}$, the shallowest depth accessible to the ADCP. The most intense backscatter layers tended to lie just above the typical depth (1900-2100 m) of the neutrally buoyant, laterally spreading plume. The plume depth varies because of spatially varying bottom depths at the different venting locations along the axial valley and possibly from topographic deflection of the currents flowing across the ridge crest (e.g., Xu and Di Iorio 2012).

In principle, an individual fish is a bigger scatterer than a copepod and is more likely to reflect sound at the frequency $(75 \mathrm{kHz})$ used. However, the deep scattering layers contain an aggregated mixture of different sized and shaped species in different orientations, which have complex but intense scattering properties not readily explained by theoretical models, but are reliably reflecting biomass captured in nets (Burd and Thomson 2012). Much of the $75 \mathrm{kHz}$ signal may be coming from larger organisms (chaetognaths, decapods, fish, and jellyfish), but we know from net tows in the 1990s that these larger scatterers are mixed in with the dominant copepods (which make up $80 \%$ of the biomass; Burd and Thomson 1995). For this reason, we are confident that the ADCPs captured the mixed species aggregations near the hydrothermal vent plumes.

\section{Seasonal migratory patterns}

Based on biological studies of the North Pacific (e.g., Goldblatt et al. 1999; Kobari and Ikeda 2001a, 2001b), the large-scale seasonal shifts in depth of the backscatter layers we observed above the vent 

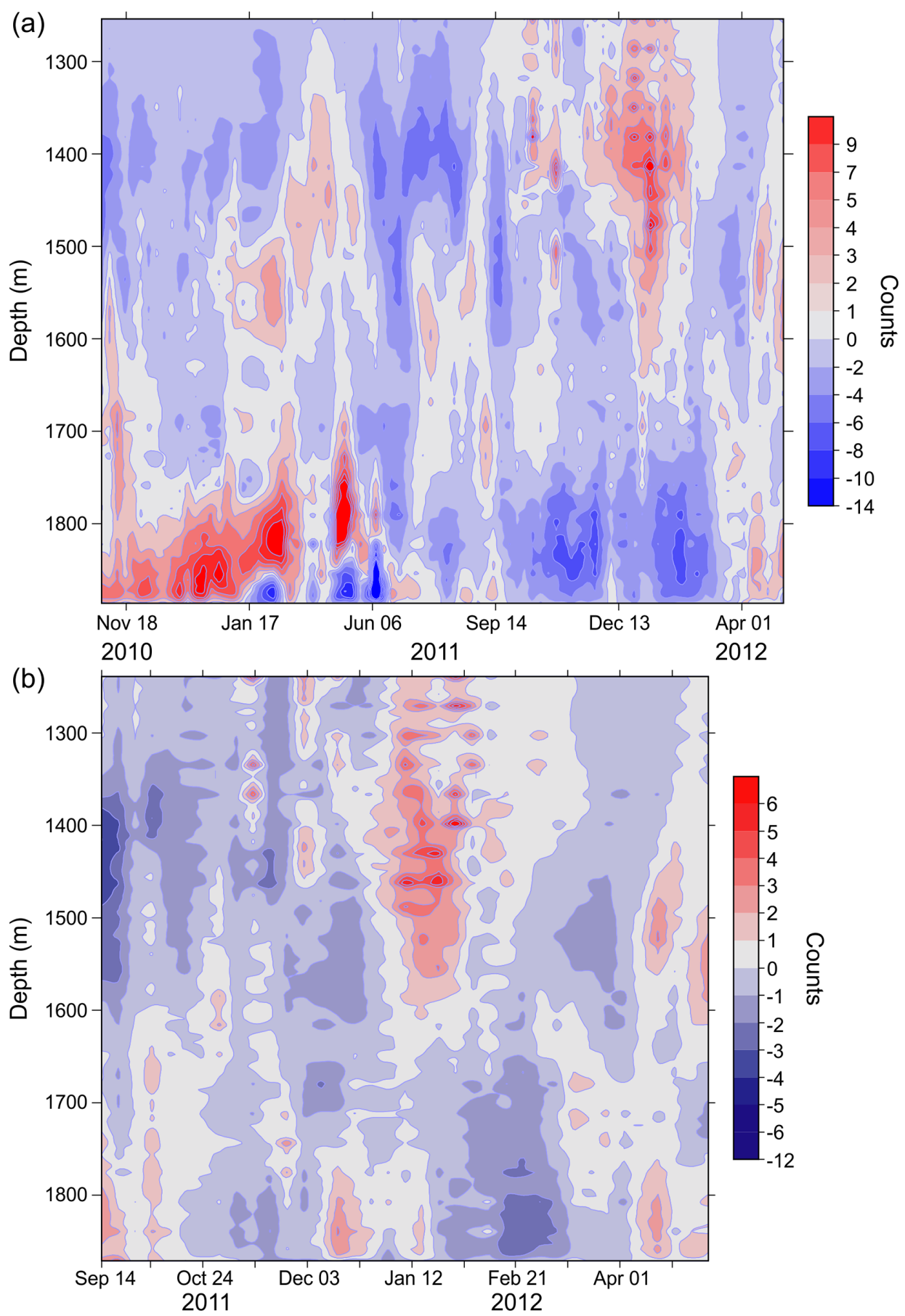

Fig. 9. Daily-averaged backscatter anomalies from Ocean Networks Canada mooring (a) RCM-NE and (b) RCM-NW.

plumes are consistent with expected life-cycle migratory patterns of the dominant upper ocean copepods and their predators. In particular, an upward movement of the DSLs observed above the level of neutrally buoyant plumes was evident in late summer and fall, resulting in concentrations of fauna at 


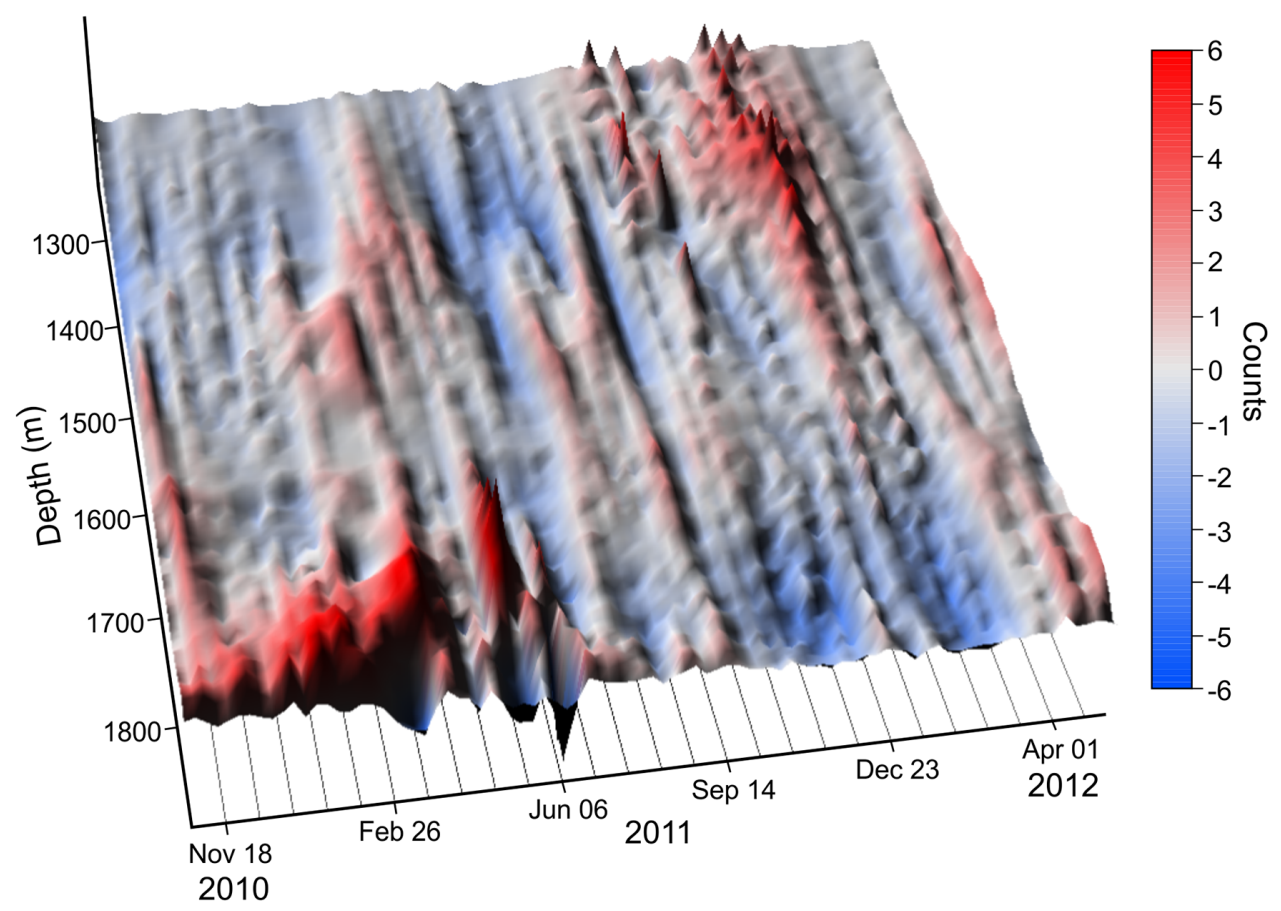

Fig. 10. Acoustic backscatter anomaly during 2010-2012 at the northeast (NE) ONC mooring shown as a surface plot (see also Fig. 9a).

much shallower depths in winter months. This is synchronous with the timing for adult maturation and reproductive incubation of the major migratory copepod taxa, which are non-feeding. A downward movement of backscatter layers towards the depth of the neutrally buoyant plume occurred in late summer/early fall, at a time when the pre-adult copepods are known to migrate to greater depths prior to reproductive development (Kobari and Ikeda 2001a, 2001b). Net samples obtained from tows near the vent plumes in the summers of 1991 to 1996 show that the dominant copepods are mainly stage V (pre-adults) (Burd et al. 1992). The active migration of late stage copepods from the upper ocean to deeper water prior to maturation is believed to minimize predation during the reproductive phase. At Endeavour Ridge, there is isotopic evidence that these late stage copepods resume feeding (Burd et al. 2002) near the neutrally buoyant plumes, presumably to increase their reproductive output (Burd and Thomson 1995, 2015).

In accordance with typical life cycles of the dominant migratory copepod species, it is expected that overall water column biomass should progressively decline from early fall through early spring, as the reproductive copepod adults release eggs and die. This pattern has been noted in the northwestern Pacific (Kobari et al. 2003), but is not clearly obvious in our data. Although a decline in backscatter intensity was recorded in fall and winter 2003 and 2005 by the ADCPs on the Seabreeze moorings, there was no apparent decline in intensity in the fall and winter of 2004. Acoustic records from the upward-looking ADCPs on the ONC moorings showed that there were strong backscatter anomalies in the water column during fall and winter at depths too shallow for the Seabreeze moorings to detect. The only time of year that the near-plume backscatter layers were not present was late spring to early summer, when new copepod larvae undergo stage I-V molts in the upper ocean and very few of the adults below $1000 \mathrm{~m}$ depth are still alive (Kobari and Ikeda 1999, 2001a, 2001b). Thus, unlike previous studies, we found that there is no season during which the DSLs disappear completely from the lower water column near Endeavour Ridge. 
There is no a priori reason to assume that the deep ontogenetic migrators remain at the same depth throughout spawning and senescence. We know from previous studies (Burd and Thomson 1994, 1995) that the predators of the copepods near Endeavour Ridge (chaetognaths, shrimp, jellyfish, and small fish) also move to deep waters in early summer following their prey, so there is no safety for copepods in staying at a single depth during reproductive development. Rather, they would likely continue to migrate vertically to avoid predators. This could explain why there is a clear upward movement of the scattering layers in early fall, away from plume depth and the food source (Figs. $9 a$ and $9 b$ ). This movement may also explain why the scattering layers near vent plumes periodically appear to be spread-out in fall and early winter, a pattern which is particularly evident in data recorded by the shallower ONC moorings (Fig。 7).

Maturation and subsequent release of reproductive material from the adult copepods can occur over a period of about 6 months in late fall and winter, with the possibility that some species or portions of populations overwinter or have biannual life cycles (i.e., do not die off in winter; see Tsuda et al. 1999). It is unlikely that overwintering or biannual adults could survive for such long periods without feeding. At Endeavour Ridge, where there is a seasonal food source at the surface and a continuous food source near the vents, the life cycles of zooplankton may be altered from the expected pattern in the open Pacific Ocean. Certainly, results from this study suggest that deep aggregations of zooplankton occur all year round near the ridge, although species composition and life stages cannot be determined from this study.

\section{Cyclical backscatter intensity}

As high-frequency variations in backscatter intensity have been filtered from the processed ADCP data using a 30-h filter, our focus is restricted to cycles in the backscatter structure at periods longer than a day. Towed ADCP profiles from the Endeavour Ridge venting region clearly show that the intense positive backscatter anomalies found just above the spreading plumes at the ridge in summer months are patchy, both in space and time (Burd and Thomson 1994, 1995). Based on the long-term (decadal) backscatter data analyzed in this study, we believe that this patchiness is consistent with the periodic, 20-40-d variations in backscatter concentration observed at all moorings (ONC and Seabreeze).

The considerable spatial synchronization of cyclical backscatter patterns over the geographic range of the different moorings is evidence that the 20-40-d temporal cycles have large spatial footprints and are not locally isolated over the ridge. At plume depth, the movements of the scatterers at sites N2 and N3 appear to be highly synchronized, whereas movements at the more northerly site (Y2) are slightly offset in time (by hours) and are less coherent than those to the south. This suggests that the fauna at the northern location are responding to slightly shifted exogenous cue(s) relative to the southern locations.

\section{Non-seasonally migrating fauna}

The backscatter layer overlying the hydrothermal plumes in summer is composed primarily of upperocean copepods that migrate ontogenetically along with their predators (Burd and Thomson 1994, 1995). However, community analyses also indicate that this DSL often also includes typical deep zooplankton fauna that are not known to have any significant seasonal migration patterns. Small-scale movements in these deep-sea fauna are expected to be opportunistic in response to local stimuli such as food or predation. Presumably these deep-sea fauna also congregate near the plume to feed.

Based on net sampling work from 1991 to 1996 (Burd and Thomson 1994, 1995), the upper ocean migratory fauna typically remain above the depth of the neutrally buoyant plumes. In contrast, the mooring data examined in this study, as well as the historical towed net-ADCP data, indicate the common presence of several distinct scattering layers near the vent plumes at Endeavour Ridge. These layers consist of upper ocean migratory fauna above the plume only, as well as non-migratory deep fauna, which range from just above the plume down to near-bottom (several 
hundred meters). The near-bottom deep-sea zooplankton may be actively swimming vertically, or may be subject to vertical displacements by internal tides or topographically trapped wave motions, but are seasonally persistent features.

A near-bottom (20 mab) zooplankton/micro-nekton layer has also been observed near Endeavour Ridge by direct submersible observations (Skebo et al. 2006), with concurrent net samples indicating that these are not benthic larval forms or vent-specific fauna. Much of this visible near-bottom biomass is shrimp, eelpouts, and rattail fish, with concentrations of smaller fauna evident in net samples. Skebo et al. (2006) also suggested that the near-bottom aggregations of fauna were absent where high temperature, high volume vents emerge (the major vent orifices), but aggregate away from the direct vent outlets, as found in the Seabreeze and ONC mooring locations, which were deliberately placed away from vent orifices.

In the towed ADCP/net studies near the ridge from 1991 to 1996 (Burd and Thomson 2012, 2015), it was assumed that near-bottom backscatter measured in bins distant from the downward facing towed ADCP were related to acoustic reflections from the seafloor. These near-bottom backscatter layers were sometimes more than $50 \mathrm{~m}$ thick. For example, towed ADCP profiles from 1993 show a nearbottom (2700 m deep) DSL (Fig. 11) at several low-temperature venting fields in the Cascadia

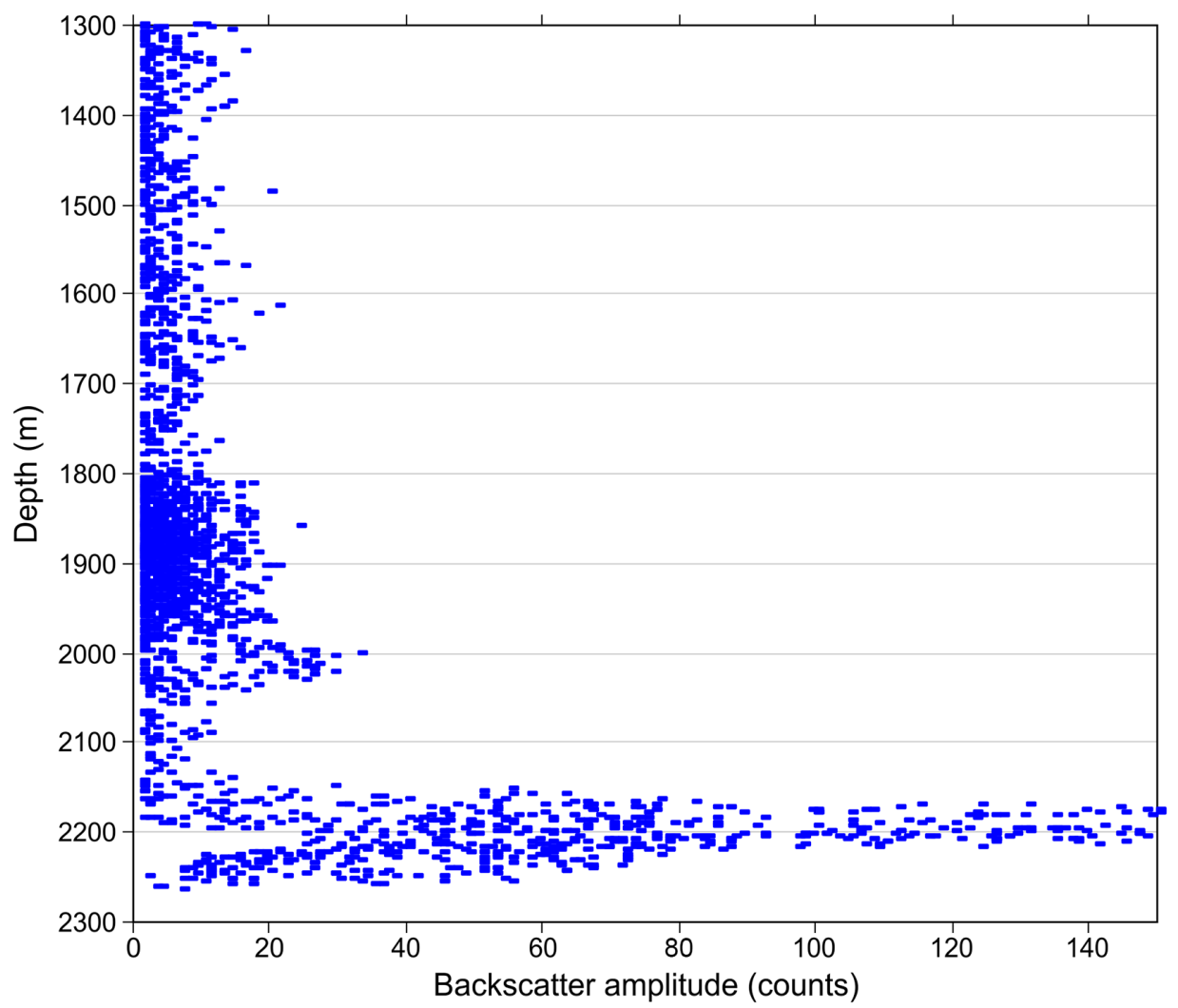

Fig. 11. Example of a July 1996 full water column acoustic Doppler current profiler (ADCP) tow deployed near the Cascadia Basin low venting sites shown in Fig. 1 (Thomson et al. 1995), showing backscatter counts (deep zooplankton scattering layers) for bins $1-25$ below the downward facing towed $153 \mathrm{kHz}$ ADCP. Sampling rate was every $4 \mathrm{~s}$. Note the dense backscatter layer between 2150 and $2250 \mathrm{~m}$ depth, in addition to a shallower feature at $2000 \mathrm{~m}$ around plume depth for the Endeavour venting sites. 
Basin (Fig. 1 and see Thomson et al. 1995). This was mistaken for bottom reflection at the time, and it was concluded that there was no deep scattering layer in the region. The moored ADCP results in the present study suggest that this assumption may have been incorrect. Based on our analyses of the acoustic backscatter data from the bottom-mounted upward-facing ADCPs on the Seabreeze moorings, positive near-bottom backscatter anomalies in the region appear to be due to deep zooplankton aggregations.

Although seasonally migratory upper ocean fauna have not been found in deeper net tows away from the axial ridge, where there is no detectable venting (Burd and Thomson 1994), the deep-sea fauna have been found aggregated in scattering layers at plume depth up to $50 \mathrm{~km}$ off-axis to the northwest of the ridge axis. Thus, unlike the migratory fauna, the endemic deep fauna appear to be advected to considerable distances off axis by currents. One possible explanation is that the upper-ocean migratory fauna are more adept at staying near the axial valley and the plume-related food source than typical deep-sea fauna. However, it is also possible that deep-water fauna are not as dependent for food on the plumes as upper-ocean animals, and might even be avoiding competition or predation by staying farther away from the plume.

\section{The role of currents on zooplankton variability}

Although it was not the purpose of this study to examine the circulation at Endeavour Ridge measured by the ADCPs, it is likely that currents play an active role in the zooplankton movement and distribution in the region. As noted previously, passive vertical displacements of up to $100 \mathrm{~m}$ due to semidiurnal tides generated over the abrupt ridge topography are expected based on earlier current meter measurements in the area (Mihaly et al. 1998) and from numerical simulations of tidal motions over nearby Axial Seamount (Xu and Lavelle 2017). It is further likely that low-frequency currents modified by the ridge topography may be responsible for passive advection of the zooplankton within the study region. This is especially true for currents at periods of 3-6 d (Fig. 12), an energetic counterclockwise frequency band with current speeds of order $0.01 \mathrm{~m} / \mathrm{s}$ known to arise from trapped waves over the ridge (e.g., Cannon and Thomson 1996). Maximum horizontal water parcel excursions due to these motions are around $1-2 \mathrm{~km}$ in both the along- and across-ridge directions, indicating that the zooplankton could be retained in the vicinity of the ridge with limited active swimming. In contrast, the $0.01 \mathrm{~m} / \mathrm{s}$ cross-axis currents observed at periods of $20-40 \mathrm{~d}$, which may be due to long wavelength topographically trapped waves or to passing mesoscale baroclinic eddies, would lead to off-axis advection of the zooplankton to distances in excess of $10 \mathrm{~km}$, making it difficult for the organisms to remain in the vicinity of the ridge without active swimming.

As a result, velocity variations over periods of days or less due to diurnal and semi-diurnal tides, windgenerated inertial currents, and trapped 3-6-d topographic waves, are commensurate with retention of zooplankton over the ridge. In contrast, motions at periods of weeks to months due to passing eddies or to large-scale topographic waves over the ridge would cause the animals to be swept far off the ridge axis, unless they are actively swimming back along a food gradient to the ridge. A separate analysis of the currents observed during the two backscatter periods is planned for a future publication.

\section{Zooplankton periodicity near moorings}

The finding of periodic 20-40-d cycles in zooplankton backscatter in all ONC and Seabreeze records suggests that some endogenous or exogenous factors are contributing to the concentration and dispersal of organisms throughout the lower water column. These factors may include:

1. The movement of zooplankton to follow patchy food gradients related to variability in plume output. Because of mixing from numerous venting sources (Baker and Massoth 1987; Di Iorio et al. 

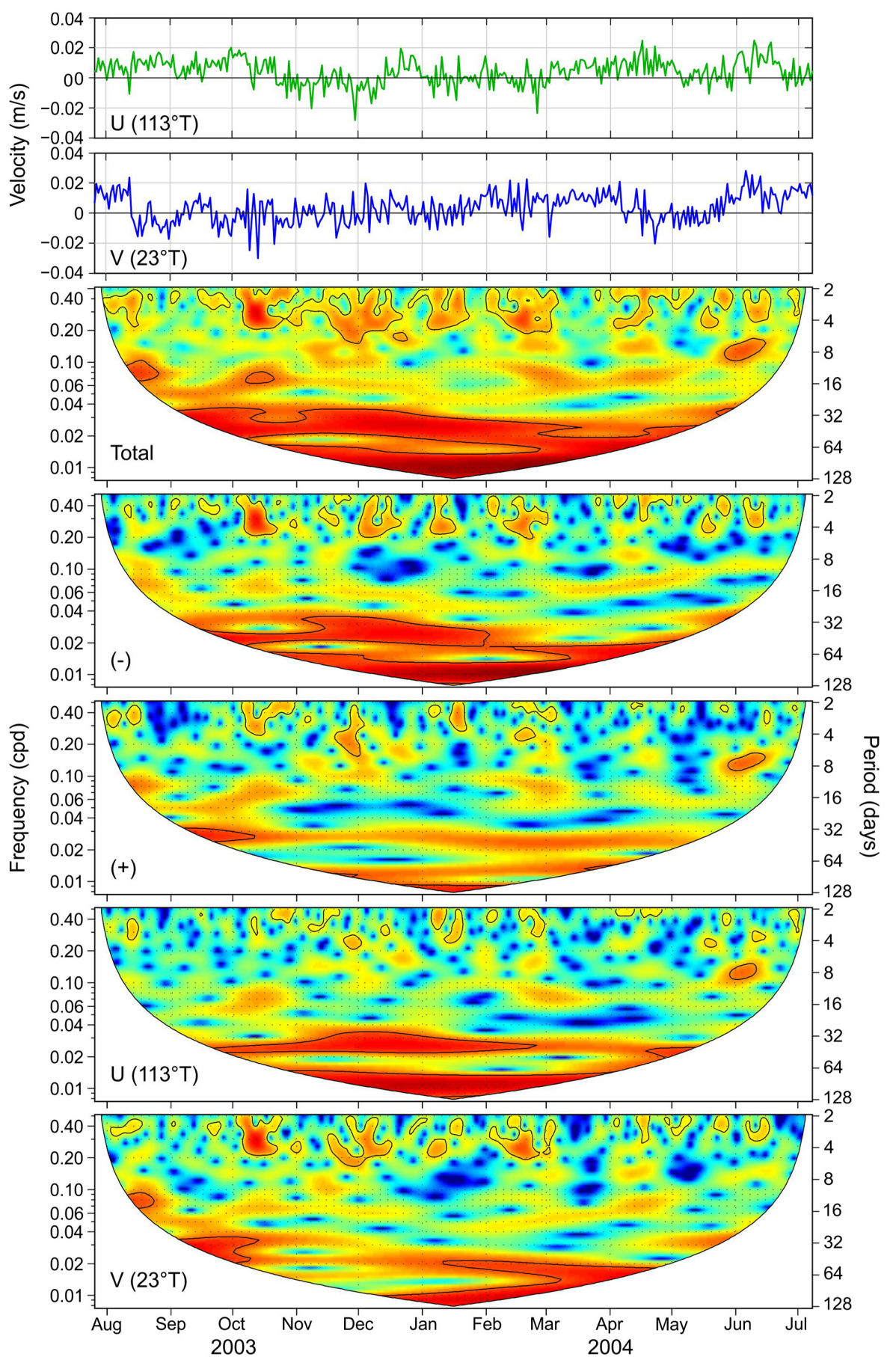

Fig. 12. Top panels: Time series of the across-ridge ( $U$; positive toward $113^{\circ}$ True) and along-ridge ( $V$; positive toward $23^{\circ}$ True) components of daily mean currents at mooring N2 from September 2003 to July 2004; Bottom panels: Time-frequency (wavelet analysis) plots of spectral power derived using the current velocity components in the top panels. The bottom two panels are the frequency versus time $(f-t)$ plots for the individual $U$, $V$ velocity components, "Total" denotes the $f-t$ plots for the combined clockwise (+) and counterclockwise (-) components of current velocity (cf. Thomson and Emery 2014). The relative spectral intensity of the current in each frequency band is color-coded from weak (dark blue) to strong (dark red). The left-hand axis shows the frequency in cycles per day (cpd) and the right-hand axis the period in days. The curved line denotes the cut-off at the $95 \%$ confidence level. The $f-t$ plots are based on a multiplefilter method, similar to Morlet wavelet analysis, as discussed by Thomson and Emery (2014). 
2012; Lavelle et al. 2013; Bemis et al. 2015), it seems likely that the laterally-spreading plume at Endeavour Ridge is consistently present. Although there are limited data available to detect tidal or seasonal changes, it has been found that particulate output from the main vent plumes at Endeavour Ridge can vary over an annual cycle by a factor of two (Dymond and Roth 1988; Kellogg 2011; Xu et al. 2014). Tidal and non-tidal bottom currents within and above the axial valley further complicate the distribution and intensity of vent plumes at Endeavour Ridge (Thomson et al. 2009). Inter-annual variability is also likely, which may affect the intensity and distribution of near plume scattering layers observed in different years. It seems unlikely that vent plume output varies at the intra-seasonal cycle of 20-40 d found in the deep scattering layers.

2. Animal aggregation by physical processes. Currents and topographic features can lead to zooplankton and micro-nekton aggregation (Dower and Brodeur 2004; Genin 2004; Sutton 2013) in frontal zones (Flint et al. 2002), near seamounts (Sutton et al. 2010), in submarine canyons (De Leo et al. 2010), and along mid-ocean ridges (Sutton et al. 2008). Venting areas of the Juan de Fuca Ridge also tend to concentrate zooplankton in a way that is not evident in surrounding non-venting regions of the ocean, resulting in enhanced biomass and production at depth (Burd et al. 1992; Burd and Thomson 1994, 1995, 2015). Although this biomass enhancement is not expected to be caused by topography (Priede et al. 2013), it is reasonable to suggest that complex ridge-related current patterns (e.g., Thomson et al. 2005, 2009) play an important role in maintaining zooplankton aggregations near vent plume food sources.

Towed ADCP profiles collected during the summer from 1991 to 1996 suggest that non-diurnal, vertical migrations were occurring between the deep epiplume layer and the bottom of the oxycline located at about 800-1000 m depth (Burd and Thomson 1994; Burd et al. 2002). A simple circulation model indicated that round-trip migrations to the upper ocean were possible without the animals being advected beyond the range of the detectable plume. Therefore, considerable short-term vertical migratory movements are possible for these animals, without them being transported away from the neutrally buoyant plumes. Such positioning and use of currents has been described for near-bottom vent larval forms (Mullineaux et al. 2013). Horizontal migration has not been described in the dominant northeast Pacific copepods, but is reasonable given that it has been documented for upper ocean meso-pelagic zooplankton and micro-nekton on diurnal cycles near Hawaii to maintain optimal positions for feeding (Benoit-Bird and Au 2004; McManus et al. 2008). Several newer 3-D acoustic methods are opening possibilities for understanding horizontal zooplankton migration patterns (Genin et al. 2005) from moored instruments.

The prevailing $(\sim 1-3 \mathrm{~cm} / \mathrm{s})$ currents within the axial valley tend to be poleward, whereas above the axial ridge they are predominantly in the opposite direction, along with strong and variable ridge-crest cross-valley currents with periods of 3-6 d (Thomson et al. 2009; and see Fig. 12), which could move epiplume zooplankton away from the vent source at a rate of about $1 \mathrm{~km}$ per day. To stay near the food source, continual or periodic horizontal swimming up the plume gradient may be required. An investigation of the currents recorded by the ADCPs and their relation to backscatter patterns will be presented in a separate study.

3. Lunar effects. Recent studies have suggested that vertical and (or) horizontal migrations over the lunar cycle are important mechanisms for foraging in zooplankton (McManus et al. 2008; Benoit-Bird et al. 2009; Ochoa et al. 2013; Last et al. 2016). Such responses are thought to be endogenous, but enhanced by light levels. Deep-sea lunar spawning cycles have also been observed, although exogenous cues could not be determined (Mercier et al. 2011). Van Haren and Compton (2013) suggest that internal circadian clocks may control observed lunar cycle migration in deep-sea $(>1000 \mathrm{~m})$ zooplankton, a pattern that could be imprinted during the larval phase in the upper ocean. In the deep ocean, lunar migration cycles may be enhanced by a cascading migratory ladder of biological cues from the upper ocean (Ochoa et al. 2013). The intra-seasonal (20-40 d) variability we observed in the Endeavour Ridge deep backscatter concentrations suggests a lingering endogenous lunar cycle, which may be modified by some exogenous factor such as the observed current patterns shown in the wavelet plots in Fig. 12. As indicated by the figure, the along- and cross-ridge components of the currents are dominated by motions at periods of 4-6 d and 20-40 d, corresponding to the dominant motions in the backscatter anomalies. The possible role of the currents in medium-scale displacement of the scatterers is highlighted by the strong clockwise rotary motions in Fig. 12 at the two dominant 
periods. Because these periods are often linked to topographically trapped current oscillations traveling along the axis of the ridge (Cannon and Thomson 1996) and to passing mesoscale eddies, advection by currents rather than lunar cycle currents may be the major factor affecting intra-seasonal zooplankton motions. This possibility has yet to be examined for the deep epiplume zooplankton.

\section{Conclusions}

Dominant meso-pelagic copepods previously documented in summer months in the northeastern Pacific are present year-round near plume depth at Endeavour Ridge. Separate deep-sea faunal scattering layers also appear to be present. Major seasonal movements of deep scattering layers are consistent with ontogenetic migratory patterns of upper ocean fauna. Within these larger scale migratory shifts, a 20-40-d cyclical pattern of zooplankton density change associated with variations in concentration, dispersal, advection or other process was evident at all moorings over the depth range ensonified. Potential reasons for this are discussed, and may include vertical and horizontal migratory movements due to endogenous imprinting of lunar cycles, or exogenous factors such as food gradients and currents around the axial ridge. Current patterns in relation to backscatter will be explored in a future publication.

\section{Acknowledgements}

The authors gratefully thank Professor Russel McDuff (University of Washington), Mr. Tom Juhász (Institute of Ocean Sciences, IOS), Dr. Steve Mihály (Ocean Networks Canada, ONC), and Mr. David Spear (IOS) for their major contributions to both the Seabreeze and ONC mooring programs. We are also grateful to Mr. Maxim Krassovski (IOS) and the personnel at ONC for helping process the large volumes of data from the two studies. Primary funding for this study was provided by Fisheries and Oceans Canada, with contributions from Ocean Networks Canada. The two anonymous reviewers are thanked for their comments and suggestions.

\section{Author contributions}

$\mathrm{BJB}$ and RET conceived and designed the study. BJB and RET performed the experiments/collected the data. BJB analyzed and interpreted the data. BJB and RET contributed resources. BJB and RET drafted or revised the manuscript.

\section{Competing interests}

The authors have declared that no competing interests exist.

\section{Supplementary materials}

The following Supplementary Material is available with the article through the journal website at doi:10.1139/facets-2018-0027.

Supplementary Material 1

Supplementary Material 2

\section{References}

Allen SE, and Thomson RE. 1993. Bottom-trapped subinertial motions over midocean ridges in a stratified rotating fluid. Journal of Physical Oceanography, 23: 566-581. DOI: 10.1175/15200485(1993)023<0566:BTSMOM>2.0.CO;2 
Baker ET, and Massoth GJ. 1987. Characteristics of hydrothermal plumes from two vent fields on the Juan de Fuca Ridge, northeast Pacific Ocean. Earth and Planetary Science Letters, 85: 59-73. DOI: $10.1016 / 0012-821 X(87) 90021-5$

Baker ET, Lavelle JW, Feely RA, Massoth GJ, Walker SL, and Lupton JE. 1989. Episodic venting of hydrothermal fluids from the Juan de Fuca Ridge. Journal of Geophysical Research: Solid Earth, 94: 9237-9250. DOI: 10.1029/JB094iB07p09237

Batchelder HP. 1985. Seasonal abundance, vertical distribution, and life history of Metridia pacifica (Copepoda: Calanoida) in the oceanic subarctic Pacific. Deep Sea Research Part A. Oceanographic Research Papers, 32: 949-964. DOI: 10.1016/0198-0149(85)90038-X

Bemis KG, Silver D, Xu G, Light R, Jackson D, Jones C, et al. 2015. The path to COVIS: a review of acoustic imaging of hydrothermal flow regimes. Deep Sea Research Part II: Topical Studies in Oceanography, 121: 159-176. DOI: 10.1016/j.dsr2.2015.06.002

Benoit-Bird KJ, and Au WWL. 2004. Diel migration dynamics of an island-associated soundscattering layer. Deep Sea Research Part I: Oceanographic Research Papers, 51: 707-719. DOI: 10.1016/j.dsr.2004.01.004

Benoit-Bird KJ, Au WWL, and Wisdoma DW. 2009. Nocturnal light and lunar cycle effects on diel migration of micronekton. Limnology and Oceanography, 54: 1789-1800. DOI: 10.4319/1o.2009. 54.5 .1789

Burd BJ, and Thomson RE. 1993. Flow volume calculations based on three-dimensional current and net orientation data. Deep Sea Research Part I: Oceanographic Research Papers, 40: 1141-1153. DOI: 10.1016/0967-0637(93)90130-U

Burd BJ, and Thomson RE. 1994. Hydrothermal venting at Endeavour Ridge: effect on zooplankton biomass throughout the water column. Deep Sea Research Part I: Oceanographic Research Papers, 41: 1407-1423. DOI: 10.1016/0967-0637(94)90105-8

Burd BJ, and Thomson RE. 1995. Distribution of zooplankton associated with the Endeavour Ridge hydrothermal plume. Journal of Plankton Research, 17: 965-997. DOI: 10.1093/plankt/17.5.965

Burd BJ, and Thomson RE. 2012. Estimating zooplankton biomass distribution in the water column near the endeavour segment of Juan de Fuca ridge using acoustic backscatter and concurrently towed nets. Oceanography, 25: 269-276. DOI: 10.5670/oceanog.2012.25

Burd BJ, and Thomson RE. 2015. The importance of hydrothermal venting to water-column secondary production in the northeast Pacific. Deep Sea Research Part II: Topical Studies in Oceanography, 121: 85-94. DOI: 10.1016/j.dsr2.2015.04.014

Burd BJ, Thomson RE, and Jamieson GS. 1992. Composition of a deep scattering layer overlying a mid-ocean ridge hydrothermal plume. Marine Biology, 113: 517-526. DOI: 10.1007/BF00349179

Burd BJ, Thomson RE, and Calvert SE. 2002. Isotopic composition of hydrothermal epiplume zooplankton: evidence of enhanced carbon recycling in the water column. Deep Sea Research Part I: Oceanographic Research Papers, 49: 1877-1900. DOI: 10.1016/S0967-0637(02)00089-4

Cannon GA, and Thomson RE. 1996. Characteristics of 4-day oscillations trapped by the Juan de Fuca Ridge. Geophysical Research Letters, 23: 1613-1616. DOI: 10.1029/96GL01370 
Cowen JP, Bertram MA, Wakeham SG, Thomson RE, Lavelle JW, Baker ET, et al. 2001. Ascending and descending particle flux from hydrothermal plumes at Endeavour Segment, Juan de Fuca Ridge. Deep Sea Research Part I: Oceanographic Research Papers, 48: 1093-1120. DOI: 10.1016/S09670637(00)00070-4

De Leo FC, Smith CR, Rowden AA, Bowden DA, and Clark MR. 2010. Submarine canyons: hotspots of benthic biomass and productivity in the deep sea. Proceedings of the Royal Society B: Biological Sciences, 277: 2783-2792. PMID: 20444722 DOI: 10.1098/rspb.2010.0462

Deines KL. 1999. Backscatter estimation using broadband acoustic Doppler current profilers. In Proceedings of the IEEE Sixth Working Conference on Current Measurement (Cat. No. 99CH36331), San Diego, California, 13 March 1999. IEEE. pp. 249-253. DOI: 10.1109/CCM.1999.755249

Di Iorio D, Lavelle JW, Rona PA, Bemis K, Xu G, Germanovich LN, et al. 2012. Measurements and models of heat flux and plumes from hydrothermal discharges near the deep seafloor. Oceanography, 25: 168-179. DOI: 10.5670/oceanog.2012.14

Dower JF, and Brodeur RD. 2004. The role of biophysical coupling in concentrating marine organisms around shallow topographies. Journal of Marine Systems, 50: 1-2. DOI: 10.1016/ j.jmarsys.2004.04.002

Dymond J, and Roth S. 1988. Plume dispersed hydrothermal particles: a time-series record of settling flux from the Endeavour Ridge using moored sensors. Geochimica et Cosmochimica Acta, 52: 2525-2536. DOI: 10.1016/0016-7037(88)90310-9

Dziak RP, Bohnenstiehl DR, Cowen JP, Baker ET, Rubin KH, Haxel JH, et al. 2007. Rapid dike emplacement leads to eruptions and hydrothermal plume release during seafloor spreading events. Geology, 35: 579-582. DOI: 10.1130/G23476A.1

Flint MV, Sukhanova IN, Kopylov AI, Poyarkova SG, and Whitledge TE. 2002. Plankton distribution associated with frontal zones in the vicinity of the Pribilof Islands. Deep Sea Research Part II: Topical Studies in Oceanography, 49: 6069-6093. DOI: 10.1016/S0967-0645(02)00334-X

Genin A. 2004. Bio-physical coupling in the formation of zooplankton and fish aggregations over abrupt topographies. Journal of Marine Systems, 50: 3-20. DOI: 10.1016/j.jmarsys.2003.10.008

Genin A, Jaffe JS, Reef R, Richter C, and Franks PJS. 2005. Swimming against the flow: a mechanism of zooplankton aggregation. Science, 308: 860-862. PMID: 15879218 DOI: 10.1126/science.1107834

Goldblatt RH, Mackas DL, and Lewis AG. 1999. Mesozooplankton community characteristics in the NE subarctic Pacific. Deep Sea Research Part II: Topical Studies in Oceanography, 46: 2619-2644. DOI: 10.1016/S0967-0645(99)00078-8

Gostiaux L, and van Haren H. 2010. Extracting meaningful information from uncalibrated backscattered echo intensity data. Journal of Atmospheric and Oceanic Technology, 27: 943-949. DOI: 10.1175/2009JTECHO704.1

Hernández-León S, and Ikeda T. 2005. A global assessment of mesozooplankton respiration in the ocean. Journal of Plankton Research, 27: 153-158. DOI: 10.1093/plankt/fbh166

Kelley DS, Carbotte SM, Caress DW, Clague DA, Delaney JR, Gill JB, et al. 2012. Endeavour Segment of the Juan de Fuca Ridge: one of the most remarkable places on earth. Oceanography, 25: 44-61. DOI: $10.5670 /$ oceanog.2012.03 
Kellogg JP. 2011. Temporal and spatial variability of hydrothermal fluxes within a mid-ocean ridge segment. Ph.D. dissertation, Pro-Quest document, University of Washington, Seattle, Washington [online]: Available from search.proquest.com/openview/01f6edf775e6cd0ce9b52e5f5ac17531/1?pqorigsite $=$ gscholar\&cbl $=18750 \&$ diss $=y$

Kobari T, and Ikeda T. 1999. Vertical distribution, population structure and life cycle of Neocalanus cristatus (Crustacea: Copepoda) in the Oyashio region, with notes on its regional variations. Marine Biology, 134: 683-696. DOI: 10.1007/s002270050584

Kobari T, and Ikeda T. 2001a. Life cycle of Neocalanus flemingeri (Crustacea: Copepoda) in the Oyashio region, western subarctic Pacific, with notes on its regional variations. Marine Ecology Progress Series, 209: 243-255. DOI: 10.3354/meps209243

Kobari T, and Ikeda T. 2001b. Ontogenetic vertical migration and life cycle of Neocalanus plumchrus (Crustacea: Copepoda) in the Oyashio region, with notes on regional variations in body sizes. Journal of Plankton Research, 23: 287-302. DOI: 10.1093/plankt/23.3.287

Kobari T, Shinada A, and Tsuda A. 2003. Functional roles of interzonal migrating mesozooplankton in the western subarctic Pacific. Progress in Oceanography, 57: 279-298. DOI: 10.1016/S00796611(03)00102-2

Landry MR, and Fagerness VL. 1988. Behavioral and morphological influences on predatory interactions among marine copepods. Bulletin of Marine Science, 43: 509-529.

Last KS, Hobbs L, Berge J, Brierley AS, and Cottier F. 2016. Moonlight drives ocean-scale mass vertical migration of zooplankton during the Arctic winter. Current Biology, 26: 244-251. PMID: 26774785 DOI: 10.1016/j.cub.2015.11.038

Lavelle JW, Di Iorio D, and Rona P. 2013. A turbulent convection model with an observational context for a deep-sea hydrothermal plume in a time-variable cross flow. Journal of Geophysical Research: Oceans, 118: 6145-6160. DOI: 10.1002/2013JC009165

Mackas DL, Batten S, and Trudel M. 2007. Effects on zooplankton of a warmer ocean: recent evidence from the Northeast Pacific. Progress in Oceanography, 75: 223-252. DOI: 10.1016/j.pocean. 2007.08.010

McManus MA, Benoit-Bird KJ, and Woodson CB. 2008. Behavior exceeds physical forcing in the diel horizontal migration of the midwater sound-scattering layer in Hawaiian waters. Marine Ecology Progress Series, 365: 91-101. DOI: 10.3354/meps07491

Mercier A, Sun Z, Baillon S, and Hamel J-F. 2011. Lunar rhythms in the deep sea: evidence from the reproductive periodicity of several marine invertebrates. Journal of Biological Rhythms, 26: 82-86. PMID: 21252369 DOI: 10.1177/0748730410391948

Mihaly SF, Thomson RE, and Rabinovich AB. 1998. Evidence for nonlinear interaction between internal waves of inertial and semidiurnal frequency. Geophysical Research Letters, 25: 1205-1208. DOI: $10.1029 / 98$ GL00722

Miller CB, and Clemons MJ. 1988. Revised life history analysis for large grazing copepods in the subarctic Pacific Ocean. Progress in Oceanography, 20: 293-313. DOI: 10.1016/0079-6611(88)90044-4

Miller CB, Frost BW, Batchelder HP, Clemons MJ, and Conway RE. 1984. Life histories of large, grazing copepods in a subarctic ocean gyre: Neocalanus plumchrus, Neocalanus cristatus, and Eucalanus 
bungii in the Northeast Pacific. Progress in Oceanography, 13: 201-243. DOI: 10.1016/0079-6611(84) 90009-0

Mullineaux LS, McGillicuddy DJ Jr, Mills SW, Kosnyrev VK, Thurnherr AM, Ledwell JR, et al. 2013. Active positioning of vent larvae at a mid-ocean ridge. Deep Sea Research Part II: Topical Studies in Oceanography, 92: 46-57. DOI: 10.1016/j.dsr2.2013.03.032

Ochoa J, Maske H, Sheinbaumc J, and Candela J. 2013. Diel and lunar cycles of vertical migration extending to below $1000 \mathrm{~m}$ in the ocean and the vertical connectivity of depth-tiered populations. Limnology and Oceanography, 58: 1207-1214. DOI: 10.4319/1o.2013.58.4.1207

Priede IG, Bergstad OA, Miller PI, Vecchione M, Gebruk A, Falkenhaug T, et al. 2013. Does presence of a mid-ocean ridge enhance biomass and biodiversity? PLoS ONE, 8: e61550. PMID: 23658696 DOI: 10.1371/journal.pone.0061550

Robison BH. 2004. Deep pelagic biology. Journal of Experimental Marine Biology and Ecology, 300: 253-272. DOI: 10.1016/j.jembe.2004.01.012

Skebo K, Tunnicliffe V, Garcia Berdeal I, and Johnson HP. 2006. Spatial patterns of zooplankton and nekton in a hydrothermally active axial valley on Juan de Fuca Ridge. Deep Sea Research Part I: Oceanographic Research Papers, 53: 1044-1060. DOI: 10.1016/j.dsr.2006.03.001

Sutton TT. 2013. Vertical ecology of the pelagic ocean: classical patterns and new perspectives. Journal of Fish Biology, 83: 1508-1527. PMID: 24298949 DOI: 10.1111/jfb.12263

Sutton TT, Porteiro FM, Heinoc M, Byrkjedal I, Langhelle G, Anderson CIH, et al. 2008. Vertical structure, biomass and topographic association of deep-pelagic fishes in relation to a mid-ocean ridge system. Deep Sea Research Part II: Topical Studies in Oceanography, 55: 161-184. DOI: 10.1016/ j.dsr2.2007.09.013

Sutton TT, Porteiro FM, Anderson CIH, Horne J, Byrkjedal I, Heino M, et al. 2010. Deep-pelagic fish interactions with seamounts and mid-ocean ridges. In Proceedings of an International SymposiumInto the Unknown, Researching Mysterious Deep-Sea Animals. Edited by K Sato. Okinawa Churaumi Aquarium, Okinawa, Japan. pp. 53-68.

Terazaki M, and Miller CB. 1986. Life history and vertical distribution of pelagic chaetognaths at Ocean Station P in the subarctic Pacific. Deep Sea Research Part A. Oceanographic Research Papers, 33: 323-337. DOI: 10.1016/0198-0149(86)90094-4

Thomson RE, and Emery WJ. 2014. Data analysis methods in physical oceanography. 3rd edition. Elsevier Science, Amsterdam, the Netherlands; London, UK; and New York, New York. 716 p.

Thomson RE, Gordon RL, and Dymond J. 1989. Acoustic Doppler current profiler observations of a mid-ocean ridge hydrothermal plume. Journal of Geophysical Research: Oceans, 94: 4709-4720. DOI: 10.1029/JC094iC04p04709

Thomson RE, Roth SE, and Dymond J. 1990. Near-inertial motions over a mid-ocean ridge: effects of topography and hydrothermal plumes. Journal of Geophysical Research: Oceans, 95: 7261-7278. DOI: 10.1029/JC095iC05p07261

Thomson RE, Gordon RL, and Dolling AG. 1991. An intense acoustic scattering layer at the top of a mid-ocean ridge hydrothermal plume. Journal of Geophysical Research: Oceans, 96: 4839-4844. DOI: 10.1029/90JC02692 
Thomson RE, Burd BJ, Dolling AG, Gordon RL, and Jamieson GS. 1992. The deep scattering layer associated with the Endeavour Ridge hydrothermal plume. Deep Sea Research Part A. Oceanographic Research Papers, 39: 55-73. DOI: 10.1016/0198-0149(92)90020-T

Thomson RE, Davis EE, and Burd BJ. 1995. Hydrothermal venting and geothermal heating in Cascadia Basin. Journal of Geophysical Research: Solid Earth, 100: 6121-6141. DOI: 10.1029/ 95JB00030

Thomson RE, Mihaly SF, Rabinovich AB, McDuff RE, Veirs SR, and Stahr FR. 2003. Constrained circulation at Endeavour Ridge facilitates colonization by vent larvae. Nature, 424: 545-549. PMID: 12891356 DOI: $10.1038 /$ nature01824

Thomson RE, Subbotina MM, and Anisimov MV. 2005. Numerical simulation of hydrothermal vent-induced circulation at Endeavour Ridge. Journal of Geophysical Research: Oceans, 110: C01004. DOI: 10.1029/2004JC002337

Thomson RE, Subbotina MM, and Anisimov MV. 2009. Numerical simulation of mean currents and water property anomalies at Endeavour Ridge: hydrothermal versus topographic forcing. Journal of Geophysical Research: Oceans, 114: C09020. DOI: 10.1029/2008JC005249

Tsuda A, Saito H, and Kasai H. 1999. Life histories of Neocalanus flemingeri and Neocalanus plumchrus (Calanoida: Copepoda) in the western subarctic Pacific. Marine Biology, 135: 533-544. DOI: $10.1007 / \mathrm{s} 002270050654$

van Haren H, and Compton TJ. 2013. Diel vertical migration in deep sea plankton is finely tuned to latitudinal and seasonal day length. PLoS ONE, 8: e64435. PMID: 23717613 DOI: 10.1371/ journal.pone.0064435

Wakeham SG, Cowen JP, Burd BJ, and Thomson RE. 2001. Lipid-rich ascending particles from the hydrothermal plume at Endeavour Segment, Juan de Fuca Ridge. Geochimica et Cosmochimica Acta, 65: 923-939. DOI: 10.1016/S0016-7037(00)00580-9

Xu G, and Di Iorio D. 2012. Deep sea hydrothermal plumes and their interaction with oscillatory flows. Geochemistry, Geophysics, Geosystems, 13: Q0AJ01. DOI: 10.1029/2012GC004188

Xu G, and Lavelle JW. 2017. Circulation, hydrography, and transport over the summit of Axial Seamount, a deep volcano in the Northeast Pacific. Journal of Geophysical Research: Oceans, 122: 5404-5422. DOI: 10.1002/2016JC012464

Xu G, Jackson DR, Bemis KG, and Rona PA. 2014. Time-series measurement of hydrothermal heat flux at the Grotto mound, Endeavour Segment, Juan de Fuca Ridge. Earth and Planetary Science Letters, 404: 220-231. DOI: 10.1016/j.epsl.2014.07.040 